Article

\title{
Effects of Nozzle Configuration on Rock Erosion Under a Supercritical Carbon Dioxide Jet at Various Pressures and Temperatures
}

\author{
Man Huang 1,2,3, Yong Kang ${ }^{1,2,3, *}$, Xiaochuan Wang ${ }^{1,2,3}$, Yi Hu ${ }^{1,2,3}$, Deng $\mathrm{Li}^{1,2,3}$, Can Cai ${ }^{1,2,3}$ \\ and Feng Chen 1,2,3 \\ 1 Key Laboratory of Hydraulic Machinery Transients, Ministry of Education, Wuhan University, \\ Wuhan 430072, China; mhuang@whu.edu.cn (M.H.); wangxiaochuanwhu@163.com (X.W.); \\ huyiwhu@163.com (Y.H.); lidengwhu@163.com (D.L.); caicanwhu@163.com (C.C.); \\ chenfengwhu@163.com (F.C.) \\ 2 Hubei Key Laboratory of Waterjet Theory and New Technology, Wuhan University, Wuhan 430072, China \\ 3 School of Power and Mechanical Engineering, Wuhan University, Wuhan 430072, China \\ * Correspondence: kangyong@whu.edu.cn; Tel.: +86-027-6877-4906
}

Academic Editor: Jose Augusto Paixao Coelho

Received: 18 May 2017; Accepted: 9 June 2017; Published: 12 June 2017

\begin{abstract}
The supercritical carbon dioxide $\left(\mathrm{SC}-\mathrm{CO}_{2}\right)$ jet offers many advantages over water jets in the field of oil and gas exploration and development. To take better advantage of the $\mathrm{SC}-\mathrm{CO}_{2}$ jet, effects of nozzle configuration on rock erosion characteristics were experimentally investigated with respect to the erosion volume. A convergent nozzle and two Laval nozzles, as well as artificial cores were employed in the experiments. It was found that the Laval nozzle can enhance rock erosion ability, which largely depends on the pressure and temperature conditions. The enhancement increases with rising inlet pressure. Compared with the convergent nozzle, the Laval-1 nozzle maximally enhances the erosion volume by $10 \%, 21.2 \%$ and $30.3 \%$ at inlet pressures of 30,40 and $50 \mathrm{MPa}$, respectively; while the Laval-2 nozzle maximally increases the erosion volume by $32.5 \%, 49.2 \%$ and $60 \%$. Moreover, the enhancement decreases with increasing ambient pressure under constant inlet pressure or constant pressure drop. The growth of fluid temperature above the critical value can increase the enhancement. In addition, the jet from the Laval-2 nozzle with a smooth inner profile always has a greater erosion ability than that from the Laval-1 nozzle.
\end{abstract}

Keywords: supercritical carbon dioxide $\left(\mathrm{SC}-\mathrm{CO}_{2}\right)$ jet; nozzle configuration; rock erosion; erosion volume; pressure and temperature conditions

\section{Introduction}

The application of supercritical carbon dioxide $\left(\mathrm{SC}-\mathrm{CO}_{2}\right)$ has achieved obvious progress during the last few decades, stimulated by the demand of a wide range of industries that have recognized the incomparable advantages of SC-CO fluid [1]. $\mathrm{SC}-\mathrm{CO}_{2}$ is an intermediate state between gas and liquid for carbon dioxide when the pressure and temperature are both above the critical point $\left(P_{\mathrm{c}}=7.38 \mathrm{MPa}\right.$ and $T_{\mathrm{c}}=304.13 \mathrm{~K}$, respectively; the subscript " $\mathrm{c}$ " indicates the critical value.) [2]. It has many unique properties, such as high density, high diffusivity, low viscosity, high absorptive capacity by rock substances and so on, which make $\mathrm{SC}-\mathrm{CO}_{2}$ very suitable for the exploitation of oil and gas reservoirs as a working fluid [3-6]. In more specific terms, high density can provide enough power for downhole drilling tools. Low viscosity can reduce the friction loss during the drilling fluid circulation. High diffusivity can improve the rock erosion efficiency. Furthermore, high absorptive capability by rock substances can lead to greater extraction of hydrocarbons and enhance recovery. In addition, 
using SC- $-\mathrm{CO}_{2}$ as a working fluid in drilling and completion engineering will contribute to reducing greenhouse gas emissions and pollution of water resources [7,8]. To make better use of $\mathrm{SC}-\mathrm{CO}_{2}$ fluid in the field of oil and gas development, different kinds of technologies using $\mathrm{SC}-\mathrm{CO}_{2}$ fluid have been invented, like SC-CO flooding, SC- $\mathrm{CO}_{2}$ fracturing, $\mathrm{SC}-\mathrm{CO}_{2}$ coiled tubing drilling, $\mathrm{SC}-\mathrm{CO}_{2}$ jets, and so on. Among them, the $\mathrm{SC}-\mathrm{CO}_{2}$ jet, which can be more efficient in eroding rocks than the water jet under the same conditions, has been the subject of numerous studies [9-18]. The most attractive point of this novel jet technology is that by taking full advantage of the high diffusivity of $\mathrm{SC}-\mathrm{CO}_{2}$, it can produce an effective jet with a strong ability to erode rock without using any devices for increasing the inlet pressure in the drilling systems. Simultaneously, the jet medium, $\mathrm{SC}-\mathrm{CO}_{2}$, can play a role in protecting reservoirs and enhance recovery during the drilling process.

In the late 1990s, Kolle [19] first experimentally studied the rock erosion characteristics of the SC- $\mathrm{CO}_{2}$ jet, for the purpose of overcoming the technical problems encountered in water jet assisted coiled tubing drilling. He found that the $\mathrm{SC}-\mathrm{CO}_{2}$ jet will cut hard shale, marble and granite at much lower pressure than a water jet. In more specific terms, the $\mathrm{SC}-\mathrm{CO}_{2}$ jet threshold pressure is $2 / 3$ that of water jet in the granite and less than half that of water jet in the shale. Moreover, the rate of penetration in the Mancos Shale with $\mathrm{SC}-\mathrm{CO}_{2}$ was 3.3 times the rate using water and the drilling specific energy is only about $20 \%$ that observed while drilling with water. Then, based on this study, to make a better use of the SC- $\mathrm{CO}_{2}$ jet by maximally enhancing the erosion capability, many researchers are focusing on the rock erosion characteristics, jet types, and flow field of the $\mathrm{SC}-\mathrm{CO}_{2}$ jet as well as the impacting characteristics, aiming at optimizing the operating conditions and revealing the rock erosion mechanism. For instance, an experimental study was performed by $\mathrm{Du}$ et al. [9] to understand the relationship of the rock erosion performance of the $\mathrm{SC}-\mathrm{CO}_{2}$ jet with the various influencing factors by the use of a well-designed experimental setup. They concluded that there exist optimal standoff distance and nozzle diameter to achieve the strongest rock erosion capability for the $\mathrm{SC}-\mathrm{CO}_{2}$ jet. The increase in inlet pressure can significantly improve the rock erosion capacity of the $\mathrm{SC}-\mathrm{CO}_{2}$ jet. It should be noted that standoff distance, $S$, was defined as the distance from the exit of the nozzle to the surface of the specimen. Also, to further reveal the rock erosion law using the $\mathrm{SC}-\mathrm{CO}_{2}$ jet and establish a theoretical basis for better application of the $\mathrm{SC}-\mathrm{CO}_{2}$ jet in drilling engineering, a large number of rock erosion experiments was conducted by Wang et al. [12]. They found that with the increasing ambient pressure, the rock erosion efficiency of the $\mathrm{SC}-\mathrm{CO}_{2}$ jet can reach the maximum when the ambient pressure is around the critical pressure under constant pressure difference, and the rotary speed of the core sample has no substantial influence on the erosion depth, but has an effect on the average width of eroded grooves. Besides, for the sake of better applying the $\mathrm{SC}-\mathrm{CO}_{2}$ jet in shale gas drilling, the microscopic changes between the original shale samples and the samples eroded by the $\mathrm{SC}-\mathrm{CO}_{2}$ jet were studied by Huang et al. [20]. They found that the surface of the shale sample impacted by the $\mathrm{SC}-\mathrm{CO}_{2}$ jet exhibits a grid-like failure. The sample is broken into layers of large volume overall as a whole. Also, the mechanical strength of the shale sample is reduced by the erosion of shale mineral induced by SC- $\mathrm{CO}_{2}$. Moreover, to clarify the rock failure mechanism and change of pore structure, rock erosion experiments using the $\mathrm{SC}-\mathrm{CO}_{2}$ jet and $\mathrm{SEM}$ observations were carried out on different rocks by $\mathrm{He}$ et al. [21]. The results showed that rock erosion by $\mathrm{SC}-\mathrm{CO}_{2}$ jet impingement is mainly in the brittle tensile failure mechanism, accompanied with the shear failure in particular locations such as the edge of the jet impinging area.

Then, a tangential injection type swirl jet nozzle was used by Du et al. [22] to investigate the rock erosion characteristics of a SC- $\mathrm{CO}_{2}$ swirl jet. The results showed that the optimum number of tangential injected entrances to achieve the best rock erosion effect for the jet is three and the optimum standoff distance is twice the nozzle diameter. Similarly, to simultaneously utilize the characteristics of both the swirling jet and conventional round jet, combined swirling and round jet nozzles were designed, and rock erosion experiments using $\mathrm{SC}-\mathrm{CO}_{2}$ combined with swirling and round jets using the nozzles were conducted by Tian et al. [23]. Their experimental results illustrated that the rock erosion efficiency of the SC- $\mathrm{CO}_{2}$ combined with swirling and round jets is $42.9 \%$ higher than that of 
the conventional water jet, and the combined jet can lead to the occurrence of rock mass breakaway. Simultaneously, to improve the erosion capacity of the $\mathrm{SC}-\mathrm{CO}_{2}$ jet, the influence of nano-silica additive on the rock erosion characteristics was experimentally investigated by Huang et al. [15]. They found that an appropriated amount of nano-silica additive can greatly enhance the erosion ability of the jet, and the effect on the erosion capability largely depends on the operating conditions.

On the other hand, for the purpose of figuring out the impact characteristics of the SC- $\mathrm{CO}_{2}$ jet and the influence of parameters on the impact characteristics, Cheng et al. [24] performed a systematical simulation to study the three-dimension flow field of $\mathrm{SC}-\mathrm{CO}_{2}$ jet using a computational fluid dynamic method. They concluded that a $\mathrm{SC}-\mathrm{CO}_{2}$ jet can generate stronger impact pressure than water jet under the same conditions. With the increase of standoff distance, the impact pressure of the SC-CO jet decreases, while the impact scope increases. Similarly, Wang et al. [17] theoretically explored the flow characteristics of a SC- $\mathrm{CO}_{2}$ jet using the computational fluid dynamics method, and they concluded that the SC- $\mathrm{CO}_{2}$ jet has a higher impact velocity than that of the water jet under the same conditions and the maximum velocity of the $\mathrm{SC}-\mathrm{CO}_{2}$ jet increases with growing fluid temperature. Besides, a computational fluid dynamics model that includes the real gas effects of $\mathrm{CO}_{2}$ was used by Long et al. [25] to study the impinging flow field of the $\mathrm{SC}-\mathrm{CO}_{2}$ jet in the bottom hole. Their simulation results showed that the Joule-Thompson throttling effects are much more prominent at higher inlet fluid temperature and larger pressure drops. Additionally, the abrasive $\mathrm{SC}-\mathrm{CO}_{2}$ jet, formed by adding solid particles into the $\mathrm{SC}-\mathrm{CO}_{2}$ jet, was numerically simulated by He et al. [16], and they found that the two-phase axial velocities of the abrasive $\mathrm{SC}-\mathrm{CO}_{2}$ jet is much higher than those of the abrasive water jet. Moreover, by methods of laboratory experiment and numerical simulation, Wang et al. [18] studied the bottom hole pressure and temperature distributions during the $\mathrm{SC}-\mathrm{CO}_{2}$ jet drilling in detail. They confirmed that with the increase of standoff distance, the bottom hole temperature decreases while the bottom hole pressure increases first and then decreases. Besides, comprehensive methods of numerical simulations and lab experiments were carried out by Tian et al. [11] to investigate the influences of the ambient pressure and the standoff distance on the impinging pressure and perforation performance of the $\mathrm{SC}-\mathrm{CO}_{2}$ jet. They confirmed that when the pressure difference is kept constant, the effective impinging pressure hardly changes with ambient pressure, but the eroded depth increases at first and then decreases, bounded by the critical pressure of $\mathrm{SC}-\mathrm{CO}_{2}$. As the standoff distance extends, the eroded diameter increases at first and then decreases.

Although a considerable amount of research has been carried out on the SC- $\mathrm{CO}_{2}$ jet, to the best of our knowledge, there is so far little literature on how nozzle configuration influences the rock erosion performance of the jet. However, when the nozzle configuration is changed, the flow of $\mathrm{SC}-\mathrm{CO}_{2}$ fluid inside the nozzle will change, which could result in different flow characteristics of the jet ejected from the nozzle exit. Since flow characteristics of the $\mathrm{SC}-\mathrm{CO}_{2}$ jet can have a great influence on the impingement of the jet on rocks, nozzle configuration is expected to put a significant impact on the rock erosion behaviors of the $\mathrm{SC}-\mathrm{CO}_{2}$ jet. Furthermore, according to the basic theory of jet dynamics [26-30], it is well known that a Laval nozzle can easily accelerate the jet fluid medium with significant compressibility to a supersonic speed under certain conditions, which is difficult for a commonly used convergent nozzle. Also, Wang et al. [31] experimentally concluded that different types of nozzles can provide various flow velocities of the jet, and a supersonic jet without chocking can be achieved using a Laval nozzle which is beneficial for improving coating density and adhesion in wire spray. In addition, the compressibility of the fluid plays a key role in the process of fluid accelerated by a Laval nozzle [27-29]. Meanwhile, it is reported that $\mathrm{SC}-\mathrm{CO}_{2}$ has significant compressibility [32-34]. Therefore, it is reasonable to speculate that the Laval nozzle can alter the flow field of the $\mathrm{SC}-\mathrm{CO}_{2}$ jet and should have great effects on the rock erosion characteristics of the jet. Moreover, a Laval nozzle was employed by Eslamian et al. [35] to accelerate a jet to supersonic levels, then the high speed jet was used to erode cylindrical brittle gypsum deposits. The results showed that the gypsum deposits can be effectively broken by the high-speed jet issuing from the Laval nozzle and the failure behaviors of the 
asymmetric deposits depend on orientation. This is conducive to further optimizing the performance of sootblower which is used to clean fireside deposits formed on tubes in boilers.

The present paper gives an experimental investigation on the effects of nozzle configuration including a convergent nozzle, and two Laval nozzles on the rock erosion characteristics of the $\mathrm{SC}-\mathrm{CO}_{2}$ jet under various pressures and temperatures, with the purpose of enhancing the rock erosion capability of the jet. Moreover, artificial cores were applied for the experiments. It serves as a supplement to the previous related research so as to provide useful information for better applications of SC- $\mathrm{CO}_{2}$ jets.

\section{Theoretical Background}

\subsection{Acceleration Mechanisms of Compressible Flow Inside the Nozzle}

Figure 1 is a schematic diagram of the acceleration mechanism of a compressible flow inside the nozzles with different longitudinal sections. Generally, the typical longitudinal section has three main types, namely, the convergent section, the divergent section and the convergent-divergent section. The corresponding nozzles are called the convergent nozzle, the divergent nozzle, and the Laval nozzle, as shown in the Figure 1.

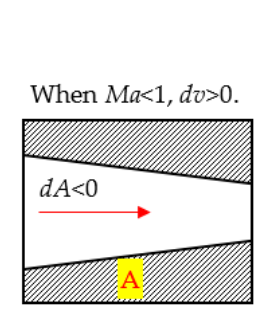

(a)

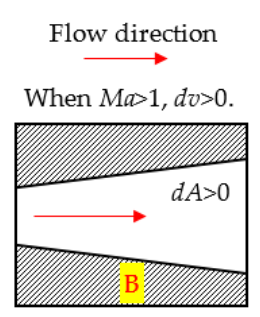

(b)

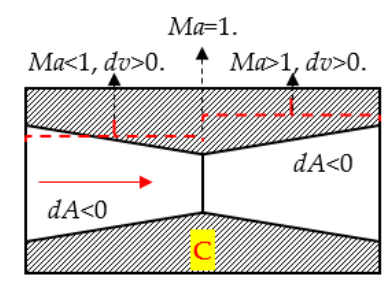

(c)

Figure 1. Schematic diagram of different types of nozzles: (a) Convergent nozzle; (b) Divergent nozzle; (c) Laval nozzle [26].

Along the flow direction, the cross-sectional area of the convergent nozzle and the divergent nozzle is getting smaller and larger, respectively; while that of the Laval nozzle reduces first and then increases. Most importantly, the acceleration of compressible flow inside a nozzle is determined by the flow speed and the type of longitudinal section of the nozzle [26-29]. To give a more detailed description, the characteristic equation derived from the conservation equations and the adiabatic equation [26,27], is introduced to make a theoretical analysis of the flow characteristics inside the nozzles with different longitudinal sections, as shown in Equation (1).

$$
\frac{d A}{A}=\left(M_{a}^{2}-1\right) \frac{d v}{v}
$$

where $A$ is cross-sectional area of the nozzle flow path $\left(\mathrm{m}^{3}\right) ; M_{a}$ is Mach number; and $v$ is flow velocity $(\mathrm{m} / \mathrm{s})$.

It can be deduced from Equation (1) that the velocity change of flow, $d v$, in the nozzle depends on the change in the cross-sectional area of the nozzle, $d A$, and the Mach number, $M_{a}$. To be more specific, when the velocity of flow is subsonic, that is, $M_{a}<1$, the fluid can be accelerated by the convergent nozzle, namely, $d A<0$. This is because the $d A<0$ and the $\left(M_{a}{ }^{2}-1\right)<0$ can make the $d v>0$, which means the flow is accelerated. It should be noted that the maximum speed that can be obtained by the subsonic flow inside the convergent nozzle is the speed of sound, which is called the choking [26,29]. On the other hand, when the velocity of flow is supersonic, that is, $M_{a}>1$, to further increase the velocity of the fluid, namely, $d v>0$, the change in cross-sectional area should meet the condition $d A>0$, that is, the flow can be accelerated in the divergent nozzle. Most importantly, to accelerate the fluid from subsonic to supersonic, the fluid should first be accelerated from subsonic to the speed of 
sound by a convergent longitudinal section, and then the sonic flow can be continuously accelerated to supersonic by a divergent longitudinal section, as shown in Figure 1c. Therefore, the fluid whose velocity is originally subsonic can be largely accelerated to a supersonic state by a Laval nozzle.

\subsection{Jet-Flow Characteristics Outside the Nozzle}

Since the fluid medium is generally accelerated from a low speed to a relatively high speed in rock erosion application, only the convergent nozzle and the Laval nozzle are discussed here. The flow characteristics of a jet emitted from the nozzle exit are related to the nozzle configuration and the pressure ratio of the ambient pressure to the inlet pressure, $P_{a} / P_{i}$, which affects the acceleration process of fluid inside the nozzle and determines the interaction of the jet fluid with the environment fluid outside the nozzle [26-29].

When a jet is formed using a convergent nozzle, the jet will be in three different flow patterns depending on the pressure ratio. For the convergent nozzle, there is a critical pressure ratio to distinguish the flow states of the jet. The critical pressure ratio can be calculated by Equation $(2)[27,29]$. To be specific, when $P_{a} / P_{i}>R_{1}$, the flow velocity at the nozzle exit is subsonic and the jet is a subsonic jet. Moreover, when $P_{a} / P_{i}=R_{1}$, the flow velocity at the nozzle exit is just the speed of sound and the jet is a sonic jet. In addition, when $P_{a} / P_{i}<R_{1}$, the flow velocity at the nozzle exit does not continue to increase and is still equal to the speed of sound, which is attributed to the chocking of the convergent nozzle. Then, the sonic flow at the nozzle exit will inflate into a supersonic jet and shock waves will occur in the jet beam. This is because the jet fluid is in an under-expanded state relative to the ambient fluid under this pressure ratio $[26,36]$.

$$
R_{1}=\frac{P_{c 1}}{P_{i}}=\left(\frac{2}{k+1}\right)^{\frac{k}{k-1}}
$$

where $R_{1}$ is critical pressure ratio of convergent nozzle; $P_{c 1}$ is critical ambient pressure of convergent nozzle (MPa); $P_{i}$ is inlet pressure (MPa); and $k$ is adiabatic exponent.

For the case of the Laval nozzle, there are five different flow states for the jet formed by the nozzle under different pressure ratios. Correspondingly, there are three critical pressure ratios, $R_{2}, R_{a 1}$, and $R_{a 2}$, which can be calculated by the Equations (3)-(5), respectively. The first case is that, when $P_{a} / P_{i}>R_{a 2}$, the flow velocity at all locations inside the nozzle is subsonic and the jet is a subsonic jet. The second case is, when $R_{a 1}<P_{a} / P_{i} \leq R_{a 2}$, the fluid can reach supersonic velocity at the divergent section near the throat of the nozzle and a normal shock wave is formed at the divergent section. The supersonic flow passes through the normal shock wave and then decelerates to subsonic flow, and finally forms a subsonic jet. The third case is, when $R_{2}<P_{a} / P_{i}<R_{a 1}$, the normal shock wave moves outward and is located outside the nozzle. A supersonic jet can be achieved under this pressure condition. It should be noted that the formation of normal shock wave is due to the over-inflated state of the jet fluid relative to the ambient fluid. The fourth case is, when $P_{a} / P_{i}=R_{2}$, a supercritical jet can be obtained through this nozzle and no shock wave will occur in the jet. In addition, the last case is, when $P_{a} / P_{i}<R_{2}$, a supercritical flow can be achieved at the nozzle exit, and the supercritical jet will be further accelerated through expansion outside nozzle exit and expansion waves will occur in the jet, which is attributed to the under-expanded state of jet fluid relative to the ambient fluid $[27,29,37]$.

$$
\begin{gathered}
R_{2}=\frac{P_{c 2}}{P_{i}}=\pi\left(\lambda_{e}\right) \\
R_{a 1}=\pi\left(\lambda_{e}\right) \frac{\frac{k+1}{k-1} \lambda_{e}^{2}-1}{\frac{k+1}{k-1}-\lambda_{e}^{2}} \\
R_{a 2}=\pi\left(\lambda_{e}^{\prime}\right)
\end{gathered}
$$


where $R_{2}, R_{a 1}$, and $R_{a 2}$ are critical pressure ratios of Laval nozzle; $P_{c 2}$ is critical ambient pressure of Laval nozzle, $\mathrm{MPa} ; \lambda_{e}$ and $\lambda_{e}{ }^{\prime}$ are supersonic and subsonic velocity coefficients, respectively; and $\pi\left(\lambda_{e}\right)$ is gas dynamics function.

From the above analysis, it is clear that nozzle configuration determines the acceleration process and flow characteristics of the jet under different pressure conditions. As a consequence, the rock erosion characteristics of the $\mathrm{SC}-\mathrm{CO}_{2}$ jets are expected to be affected as long as the flow characteristics have been influenced by nozzle configuration.

\section{Materials and Methods}

\subsection{Materials}

As for the specimen, an artificial core, which has been used by many investigators for evaluating the intensity of various jet erosion $[9,12,22,23,38,39]$, was employed for the tests because of its relatively perfect homogeneity and moderate hardness. The artificial core was made of cement, quartz sand and water in a $1 / 2 / 0.5$ mass ratio. To ensure high homogeneity of the specimen, the cement mortar was fully stirred before pouring. After 28 days of curing, the physical and mechanical properties were measured and averaged, as shown in Table 1. The diameter and height of all specimens were $100 \mathrm{~mm}$. The purity of $\mathrm{CO}_{2}$ used in the experiments was $99.8 \%$.

Table 1. Physical and mechanical properties of the specimens.

\begin{tabular}{ccccc}
\hline $\begin{array}{c}\text { Ratio, } \boldsymbol{R}_{c} \\
\text { Cement/Sand/Water }\end{array}$ & $\begin{array}{c}\text { Density, } \rho_{\mathrm{a}} \\
\left(\mathrm{g} / \mathrm{cm}^{\mathbf{3}}\right)\end{array}$ & $\begin{array}{c}\text { Compressive Strength, } \sigma_{a} \\
(\mathrm{MPa})\end{array}$ & $\begin{array}{c}\text { Modulus of Elasticity, } E_{a} \\
(\mathrm{GPa})\end{array}$ & Poisson's Ratio, $\boldsymbol{v}_{\boldsymbol{a}}$ \\
\hline $1 / 2 / 0.5$ & 2.2 & 32.8 & 19.1 & 0.23 \\
\hline
\end{tabular}

\subsection{Facilities}

Figure 2 is a schematic diagram of the experimental setup. The experiment was conducted with the use of a multifunctional SC- $\mathrm{CO}_{2}$ jet test system developed by our research team independently, and had been used in some related research $[13,15]$. The red arrows illustrate the flow direction of $\mathrm{CO}_{2}$, while the blue ones show that of hot water. The experimental system consists of a series of units, including the $\mathrm{CO}_{2}$ cartridge, the cooling unit converting gaseous $\mathrm{CO}_{2}$ to liquid to facilitate pumping, the storage tank for temporary storage of liquid $\mathrm{CO}_{2}$, the high pressure plunger pump applied to pressurize the liquid $\mathrm{CO}_{2}$, the buffer tank employed to reduce the fluid fluctuation, the chamber applied to establish the ambient pressure, the counterbalance valve used to regulate the ambient pressure, and the cyclone de-sander utilized to purify the working SC- $\mathrm{CO}_{2}$. Meanwhile, a water-bath device was used to heat the buffer tank and chamber to control the temperature of $\mathrm{CO}_{2}$. The inlet pressure and fluid temperature can be regulated continuously through the control table from 0 to $75 \mathrm{MPa}$ and 300 to $373 \mathrm{~K}$, respectively. The ambient pressure in the chamber could be increased to $45 \mathrm{MPa}$. The $\mathrm{SC}-\mathrm{CO}_{2}$ was provided through the process of pressurization and heating and then flowed through the nozzle to form a SC- $\mathrm{CO}_{2}$ jet. The jet discharged into the rock erosion chamber and then impinged on the specimen surface perpendicularly, as shown in Figure 2. 


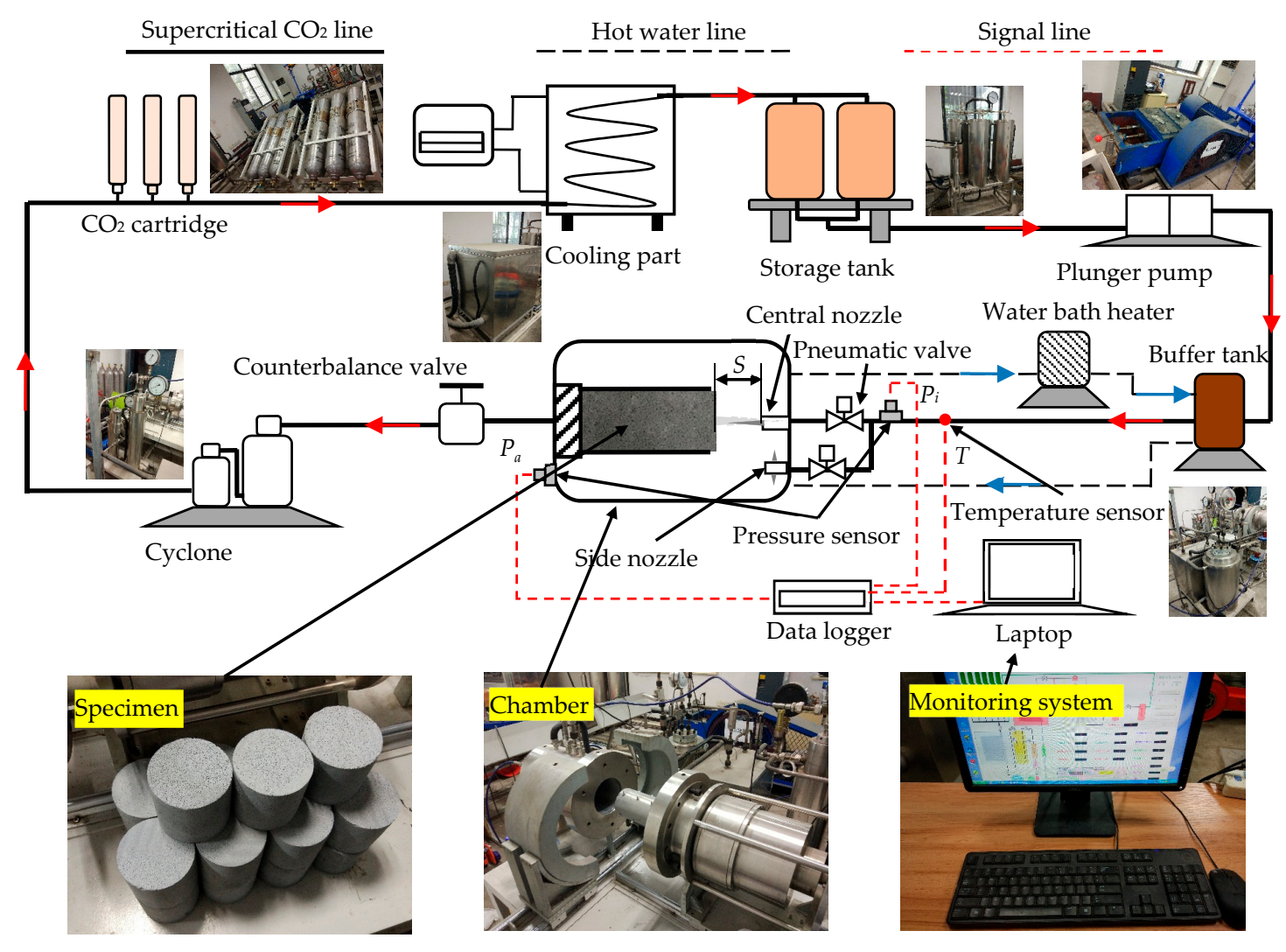

Figure 2. Schematic diagram of the rock erosion test system.

The detailed structural parameters of the nozzles used in the experiment are shown in Figure 3. Nozzle A was a commonly used convergent nozzle consisting of a contraction section and a straight pipe section. The convergent nozzle had an outlet diameter of $d_{a}=2 \mathrm{~mm}$, a convergent angle of $a_{1}=13.5^{\circ}$, and a straight pipe section length of $l_{a}=2 d_{a}$. Nozzle B was a Laval nozzle (Laval-1) which had three sections, namely, the convergent section, throat section and divergent section. The throat diameter of the Laval-1 nozzle was $d_{b 2}=2.0 \mathrm{~mm}$ and the outlet diameter was $d_{b 1}=2.66 \mathrm{~mm}$. The divergent angle of the divergent section was $a_{b 1}=10^{\circ}$, the convergent angle of the convergent section was $a_{b 2}=13.5^{\circ}$, and the length of the divergent section and the throat section are $l_{b 1}=3.8$ and $l_{b 2}=1.0 \mathrm{~mm}$, respectively. Nozzle C was a typical Laval nozzle (Laval-2) with a smooth streamlined inner profile. The nozzle had a throat diameter of $d_{c 2}=2.0 \mathrm{~mm}$, an outlet diameter of $d_{c 1}=2.66 \mathrm{~mm}$, and an inlet diameter of $d_{c 3}=5 \mathrm{~mm}$. The lengths of the divergent section, the throat and the convergent section were $l_{c 1}=3.71, l_{c 2}=0.7$ and $l_{c 3}=1.8 \mathrm{~mm}$, respectively. Moreover, the divergent section $l_{c 1}$ was designed according to the characteristic line theory [40], and the convergent section $l_{c 3}$ was designed using the commonly used empirical Witoszynski formula [41]. The two Laval nozzles had the same designed Mach number of 2 . In addition, the outside dimensions of the nozzle were the same, which were $D_{a}=D_{b}=D_{c}=12 \mathrm{~mm}$ and $L_{a}=L_{b}=L_{c}=19 \mathrm{~mm}$. 


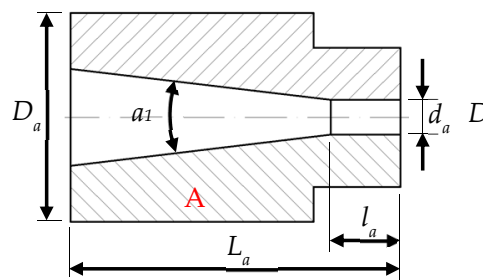

(a)

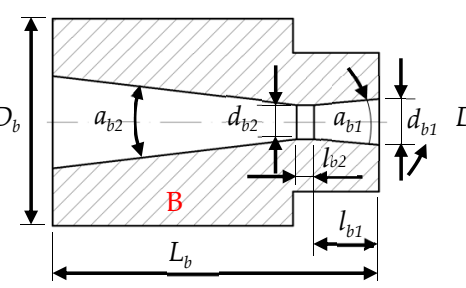

(b)

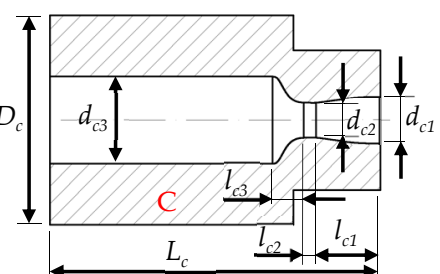

(c)

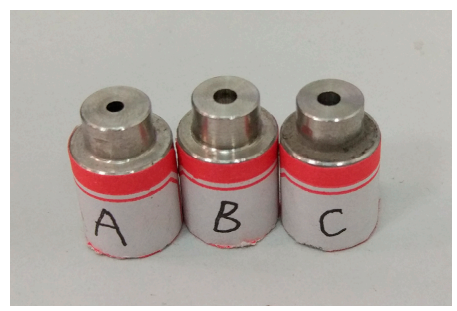

(d)

Figure 3. Detailed structural parameters of the nozzles: (a) Convergent nozzle; (b) Laval-1 nozzle; (c) Laval-2 nozzle; (d) Pictures of the nozzles.

Inlet pressure, $P_{i}$, was defined as the pressure of the flow entering into the nozzle. Ambient pressure, $P_{a}$, was defined as the pressure of the carbon dioxide in the chamber. Fluid temperature, $T$, was defined as the temperature of the fluid near the nozzle inlet. As is illustrated in Figure 2, pressure transducers (model: BD/SENSORS DMP334, BD SENSORS GmbH, Thierstein, Germany) which had been calibrated by the manufacturer with an accuracy of $0.175 \%$ FS (full scale) were positioned immediately close to the nozzle inlet and in the chamber. Simultaneously, the temperature near the nozzle inlet was measured using Omega $\mathrm{T}$ thermocouple whose total accuracy was $\pm 1 \mathrm{~K}$. The real-time data were obtained by a QuantumXMX840, (HBM, Darmstadt, Germany) data acquisition and monitoring system. During each test, the impingement on the samples by the jet would not begin until the pressures and temperatures obtained by the transducers had stabilized at the desired values. In this way, the practical application conditions for the $\mathrm{SC}-\mathrm{CO}_{2}$ jet in the bottom hole were simulated.

The aggressive intensity of the $\mathrm{SC}-\mathrm{CO}_{2}$ jet rock erosion was evaluated by measuring the volume, $V$, of the erosion hole. The erosion volume $V$ was obtained by three steps, as shown in Figure 4 . First, a certain amount of salt of density of $\rho_{\mathrm{s}}=2.165 \mathrm{~g} / \mathrm{cm}^{3}$ was weighted using an electronic balance with a resolution of $0.001 \mathrm{~g}$, and the mass was $m_{1}$. Then, the erosion hole was filled up with the salt. Finally, the remaining salt was weighted by the balance to get the mass, $m_{2}$, and the erosion volume was calculated using Equation (6). To reduce the influence of accidental factors and improve the reliability of this research, each rock erosion experiment was repeated three times and then the measured erosion volumes were averaged and used as final data to analyze the effects of nozzle configuration. In addition, the erosion depth was measured using a vernier caliper with an accuracy of $0.02 \mathrm{~mm}$.

$$
V=\frac{m_{1}-m_{2}}{\rho_{s}}
$$

where $V$ is erosion volume $\left(\mathrm{cm}^{3}\right) ; m_{1}$ is mass of salt before filling $(\mathrm{g}) ; m_{2}$ is mass of salt after filling $(\mathrm{g})$; and $\rho_{\mathrm{s}}$ is density of the salt $\left(\mathrm{g} / \mathrm{cm}^{3}\right)$. 

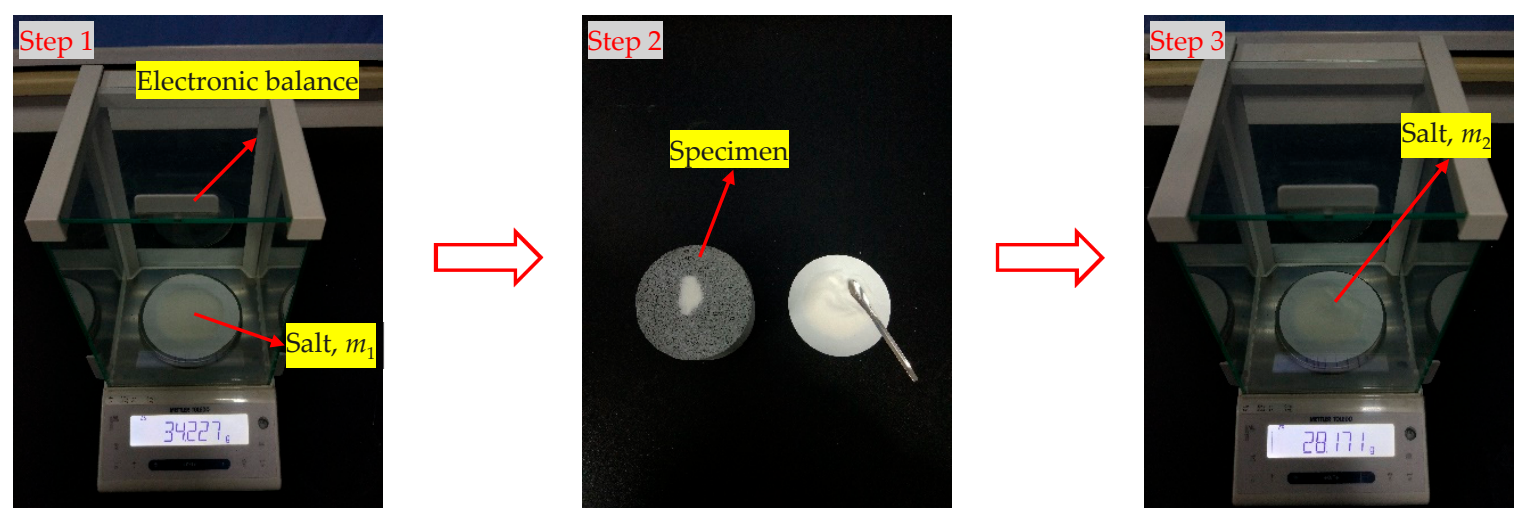

(a)
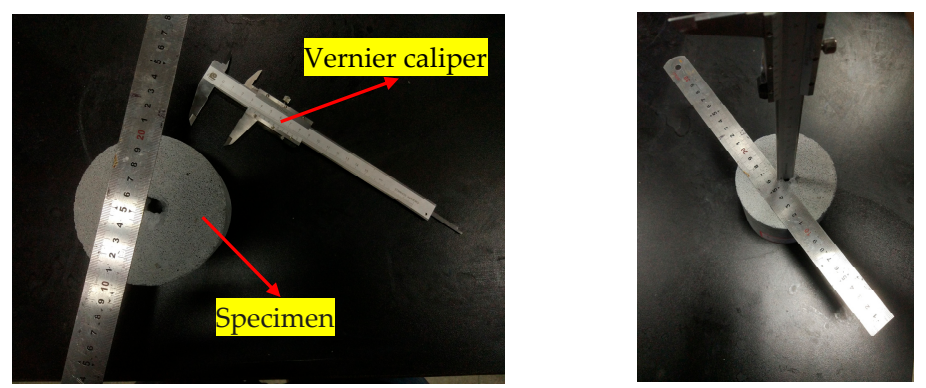

(b)

Figure 4. Schematic diagram of measurements of erosion volume and depth: (a) Erosion volume; (b) Erosion depth.

\subsection{Experimental Procedures}

The SC- $\mathrm{CO}_{2}$ jet rock erosion tests using different nozzles were conducted in the high-pressure chamber, as is shown in Figure 2. In each test, after the nozzle was installed, the standoff distance could be set by changing the holding position of the specimen. Then the chamber was closed and tightened securely to ensure that the chamber could maintain a high temperature and pressure environment.

Subsequently, the pump and water bath heater were started, and then the $\mathrm{CO}_{2}$ was pressurized and heated. When the inlet pressure and fluid temperature reached the desired value, and remained stable, the pneumatic valve controlling the side nozzle was opened and then the fluid was injected into the chamber to establish a submerged environment. Thus, the erosion effect of impingement on the specimen by a non-submerged jet could be avoided. Furthermore, the desirable ambient pressure in the chamber could be achieved by regulating the counterbalance valve.

After the desired submerged environment was established, the erosion of the specimen by the impact of the $\mathrm{SC}-\mathrm{CO}_{2}$ jet ejected from the central nozzle began and lasted for $180 \mathrm{~s}$. Finally, the ambient pressure in the chamber was released and then the erosion volume could be measured from the eroded specimen.

\subsection{Experimental Uncertainty}

The main experimental uncertainties were the accuracy of the temperature transducer acquiring the fluid temperature, the pressure transducers achieving the pressures at the nozzle inlet and in the chamber, and the repeatability of the electronic balance measuring the mass of the salt, which were less than $\pm 1 \mathrm{~K}, 0.175 \% \mathrm{FS}$, and $\pm 0.001 \mathrm{~g}$, respectively. Moreover, another source of experimental uncertainty was attributed to the method of obtaining the erosion volume. For purpose of reducing this uncertainty, the averaged erosion volumes were used in the following experimental analysis, as mentioned in Section 3.2. 


\section{Results}

Effects of nozzle configuration on the rock erosion characteristics of the $\mathrm{SC}-\mathrm{CO}_{2}$ jet were investigated at various standoff distance, inlet and ambient pressures, and fluid temperatures. A great number of specimens were tested. A qualitative analysis was carried out according to the most typical macroscopic appearances of the eroded specimens. Meanwhile, the erosion volume was plotted to quantitatively analyze the rock erosion capability of the $\mathrm{SC}-\mathrm{CO}_{2}$ jets formed by the three different nozzles.

\subsection{Macroscopic Appearances of Eroded Specimens}

Figure 5 illustrates the macroscopic appearances of specimens eroded by $\mathrm{SC}-\mathrm{CO}_{2}$ jet issuing from the three nozzles with different configurations around the optimum standoff distance under the same operating conditions. The inlet pressure was set constant as $40 \mathrm{MPa}$. The ambient pressure was set to $10 \mathrm{MPa}$, and the fluid temperature was set at $330 \mathrm{~K}$. These photos were displayed and analyzed because around the optimum standoff distance, the aggressive rock erosion intensity affected by nozzle configuration shows the largest differences with respect to erosion volume. As can be observed from the photos in Figure 5, an erosion pit is formed in the central area of the specimen by the high-speed $\mathrm{SC}-\mathrm{CO}_{2}$ jet impingement. This phenomenon suggests that the erosion of artificial core specimen caused by the $\mathrm{SC}-\mathrm{CO}_{2}$ jet is a kind of "drilling-type" damage, which has been claimed a feature of jet impact erosion for rocks with comparatively high porosity, such as limestone, sandstone and so on $[42,43]$. This kind of damage is characterized by rather deep depth with small diameter. Additionally, it can also be observed that the size of the erosion pit increases first and then decreases with the increasing standoff distance, and the maximum size can be achieved at the standoff distance of 3 and 4 for the convergent nozzle and the other two Laval nozzles, respectively. This is because, with the increase of standoff distance, the diameter of the jet beam increases while the energy of the jet declines [9]. Moreover, the macroscopic appearances of eroded specimens are in good agreement with the results of rock erosion by jets in previous related articles [15,39], indicating the reliability of this experiment.
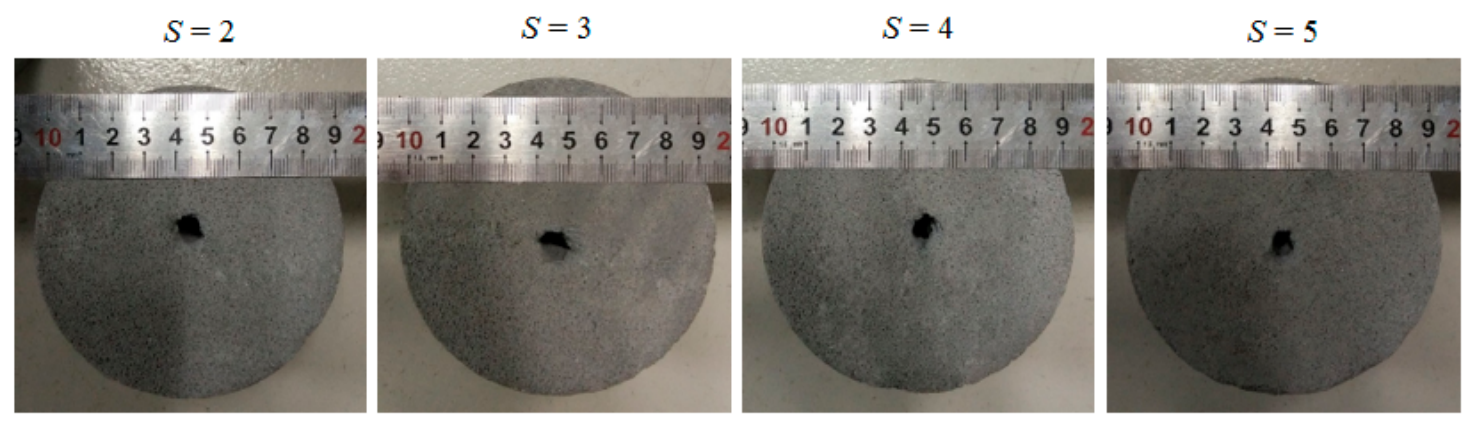

(a)
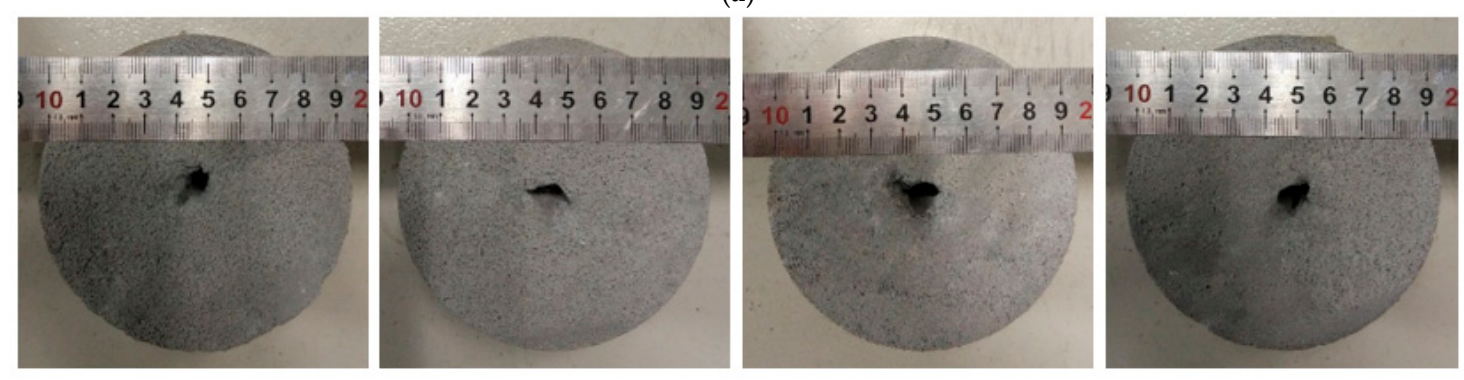

(b)

Figure 5. Cont. 

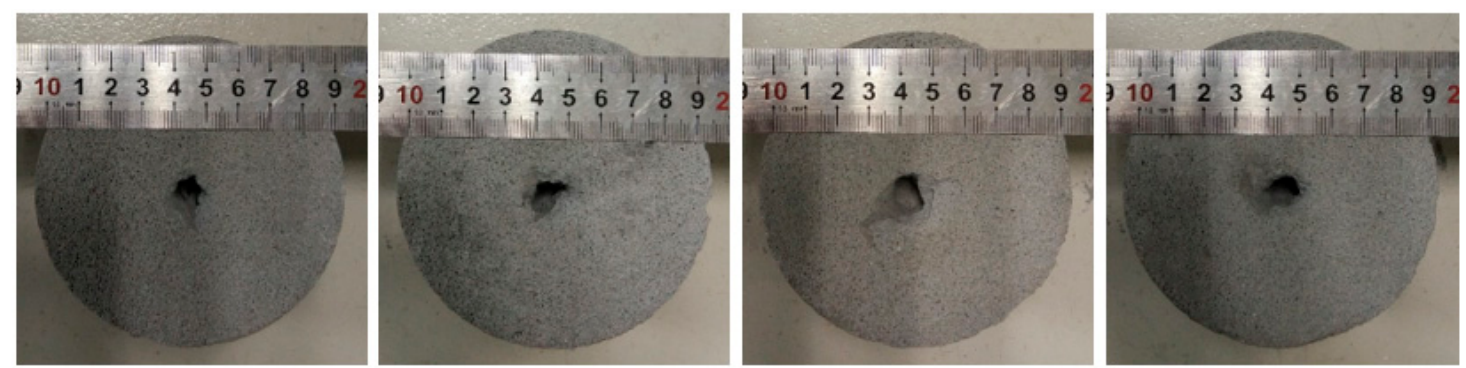

(c)

Figure 5. Photos of rock specimens after erosion: (a) Specimens eroded by the convergent nozzle; (b) Specimens eroded by the Laval-1 nozzle; (c) Specimens eroded by the Laval-2 nozzle.

It can also be observed in Figure 5 that, for the Laval nozzles, the size of the pits on the surface of the specimens are larger than that of the pits eroded by the jet discharging from the convergent nozzle at the same standoff distance, indicating that the erosion capability of the $\mathrm{SC}-\mathrm{CO}_{2}$ jet can be enhanced by the Laval nozzles. This is mainly due to the fact that the Laval nozzle with a convergent-divergent longitudinal section can make the jet have a greater impact speed, and then produce a stronger impingement on the specimens than the convergent nozzle under the same experimental conditions [26,29]. In addition, another interesting phenomenon that can be observed in the figure is that there exist small pieces of rock breakage around the erosion pits on the surface of eroded specimens when using the Laval nozzles. On the other hand, the macroscopic appearances of eroded specimens are relatively flat and smooth when using the convergent nozzle. These phenomena illustrate that, the specimens are eroded in a more intense way when using the Laval nozzles than that when employing the convergent nozzle. This difference in macroscopic appearances also suggests that the Laval nozzle with a convergent-divergent longitudinal section can enhance the impingement of the $\mathrm{SC}-\mathrm{CO}_{2}$ jet on the surface of the specimens.

\subsection{Effect of Nozzle Configuration Under Different Inlet Pressures}

In this group of experiments, the dimensionless standoff distance, $S$, was normalized by the nozzle diameter, and increased from 1 to 10 . The ambient pressure was set constant as $10 \mathrm{MPa}$, and the fluid temperature was set at $330 \mathrm{~K}$. The inlet pressures were set at 20, 30, 40 and $50 \mathrm{MPa}$, respectively.

Figure 6 illustrates the effects of nozzle configuration at various standoff distances on the rock erosion ability of the $\mathrm{SC}-\mathrm{CO}_{2}$ jet under four inlet pressures. It is shown in Figure 6 that, nozzle configuration greatly affects the rock erosion ability of the $\mathrm{SC}-\mathrm{CO}_{2}$ jet and the effects largely depend on standoff distance and inlet pressure, which is claimed by evaluating the erosion volume of the cavity on each specimen. Overall, with increasing inlet pressure, the rock erosion ability of the three test nozzle increases. This is because the higher inlet pressure allows more pressure energy to be converted into the kinetic energy of the jet, thereby enhancing the impingement of the jet. Moreover, different nozzle configurations, the convergent nozzle, or the Laval nozzles, influence the rock erosion performance differently. In more specific terms, compared with the commonly used convergent nozzle, the Laval-1 nozzle can maximally enhance the erosion volume by about $10 \%, 21.2 \%$ and $30.3 \%$, respectively, corresponding to inlet pressure of 30, 40 and $50 \mathrm{MPa}$ (Figure 6b-d); while the Laval-2 nozzle has the capability of maximally enhancing the erosion volume by about $32.5 \%, 49.2 \%$ and $60 \%$ at inlet pressure of 30, 40 and $50 \mathrm{MPa}$ (Figure $6 \mathrm{~b}-\mathrm{d}$ ), respectively. However, at inlet pressure of $20 \mathrm{MPa}$, both the two Laval nozzles turn to play an opposite role of reducing the intensity of rock erosion with the maximum erosion volume being only $71 \%$ and $88 \%$ of that of the convergent nozzle (Figure $6 a$ ). In other words, at relatively higher inlet pressure, the Laval nozzles can generally increase the rock erosion ability of the $\mathrm{SC}-\mathrm{CO}_{2}$ jet; whilst at relatively lower inlet pressures, they affect the erosion behavior in an opposite way of reduction. In addition, as the inlet pressure increases, the Laval nozzles can increase the erosion capability of the SC-CO $\mathrm{CO}_{2}$ jet more significantly. 


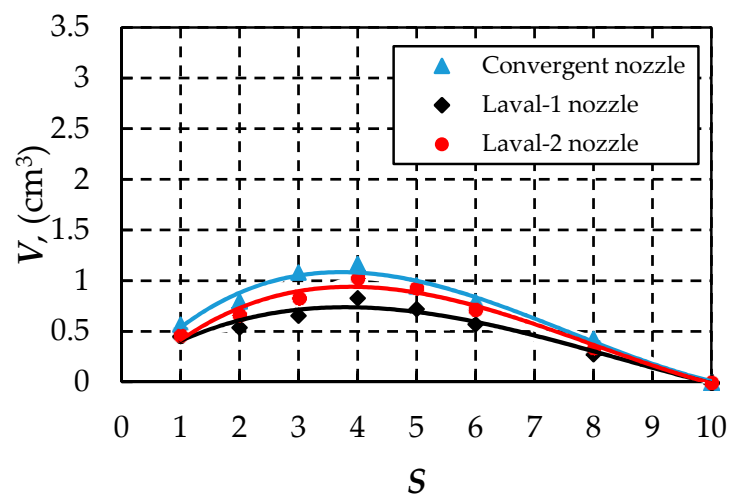

(a) $P_{i}=20 \mathrm{MPa}$

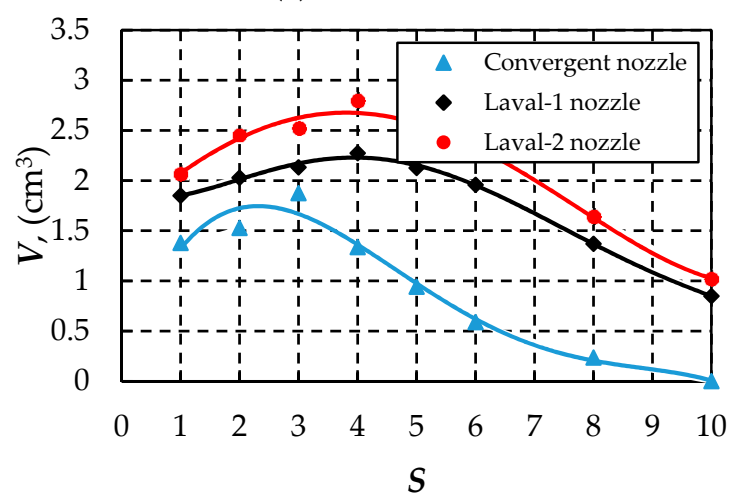

(c) $P_{i}=40 \mathrm{MPa}$

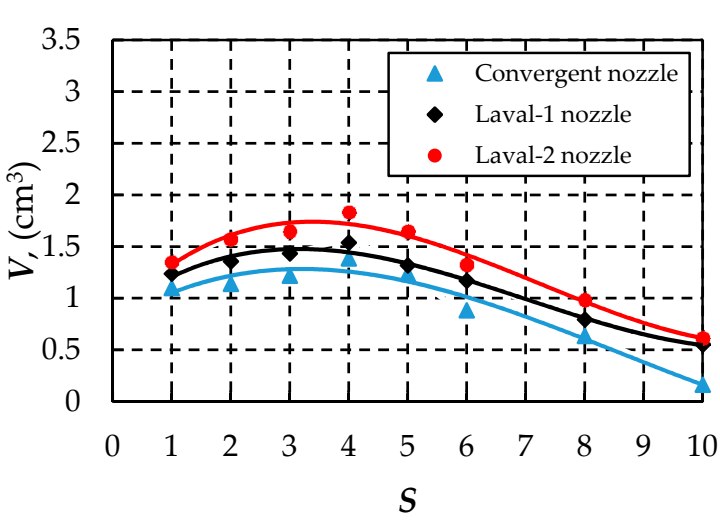

(b) $P_{i}=30 \mathrm{MPa}$

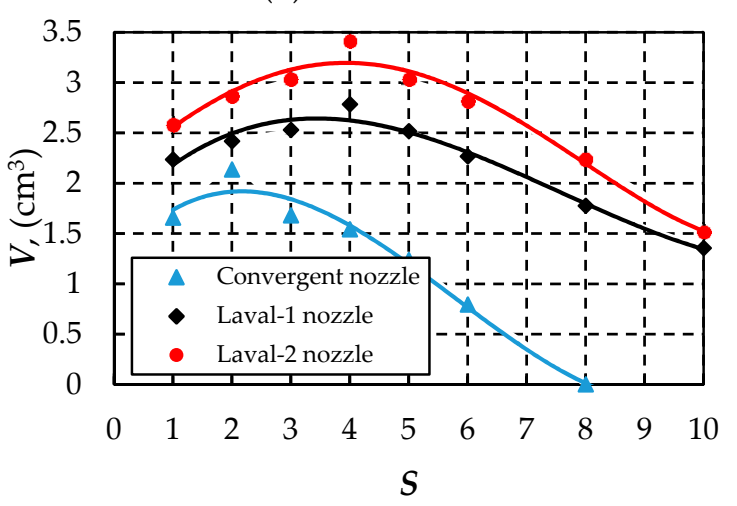

(d) $P_{i}=50 \mathrm{MPa}$

Figure 6. Effect of nozzle configuration on rock erosion volume of the supercritical carbon dioxide $\left(\mathrm{SC}-\mathrm{CO}_{2}\right)$ jet under different inlet pressures.

It can also be seen from Figure 6 that each jet has an optimum standoff distance at which position the erosion volume reaches a maximum, which means the existence of an optimum standoff distance could be a typical feature of the $\mathrm{SC}-\mathrm{CO}_{2}$ jets for erosion. This is because the undeveloped jet and backflow resistance at small standoff distance lead to large energy loss and then the poor erosion intensity. A standoff distance larger than the optimal value results in significant entrainment of the jet flow and then large energy dissipation [12]. The curves suggest that the optimal standoff distance is about 4 times the nozzle diameter for the $\mathrm{SC}-\mathrm{CO}_{2}$ jet discharging from the Laval nozzles, while it reduces from 4 to 2 with the increasing inlet pressure for the convergent nozzle. It is inferred that the jet issuing from the convergent nozzle has a smaller standoff distance range to effectively erode the specimens at relatively high inlet pressure.

\subsection{Effect of Nozzle Configuration Under Different Ambient Pressures and Constant Inlet Pressure}

Figure 7 shows the influence of nozzle configuration on the rock erosion characteristics of the SC- $\mathrm{CO}_{2}$ jet under four ambient pressures and constant inlet pressure. In this group of experiments, the inlet pressure was set constant as $40 \mathrm{MPa}$, and the fluid temperature was $330 \mathrm{~K}$. The dimensionless standoff distance was increased from 1 to 10 . The ambient pressure was sequentially increased from 2 to $26 \mathrm{MPa}$ with the increment of $8 \mathrm{MPa}$. 


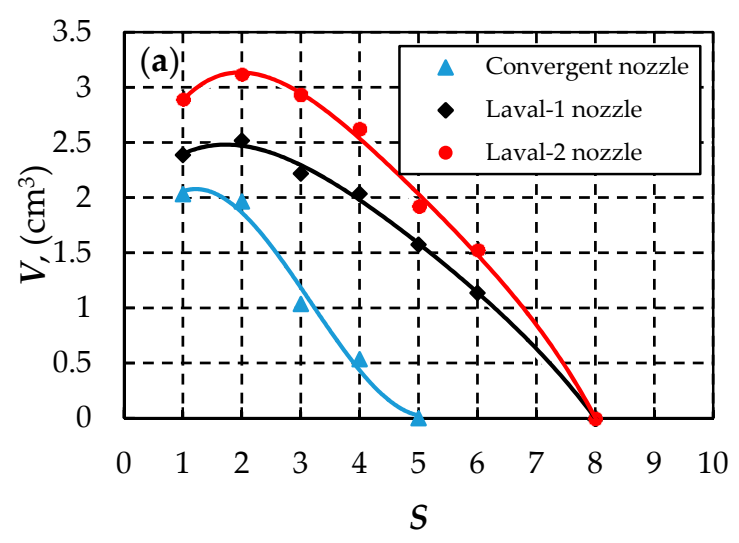

(a) $P_{a}=2 \mathrm{MPa}, P_{i}=40 \mathrm{MPa}$

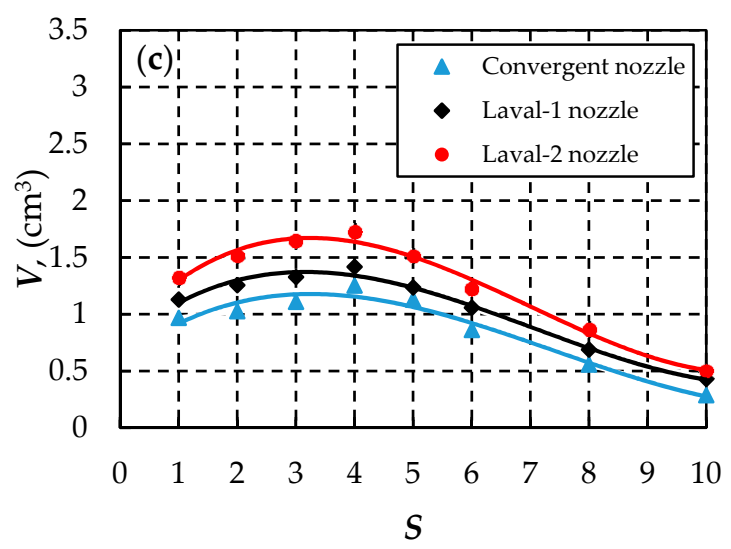

(c) $P_{a}=18 \mathrm{MPa}, P_{i}=40 \mathrm{MPa}$

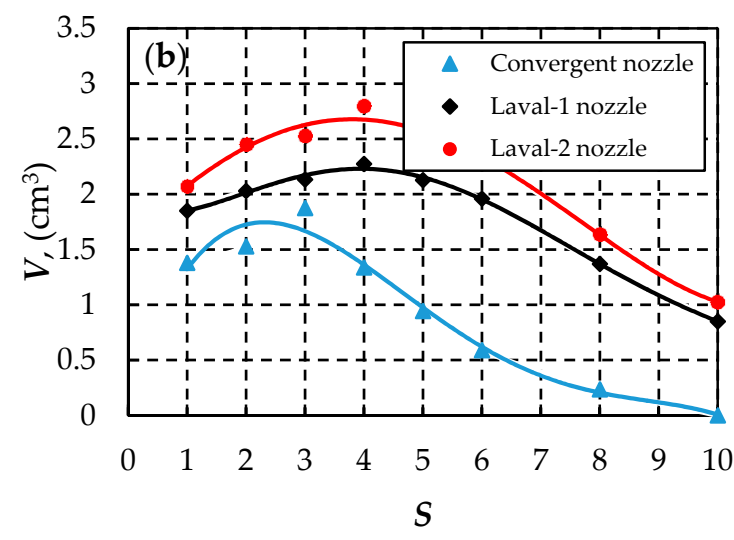

(b) $P_{a}=10 \mathrm{MPa}, P_{i}=40 \mathrm{MPa}$

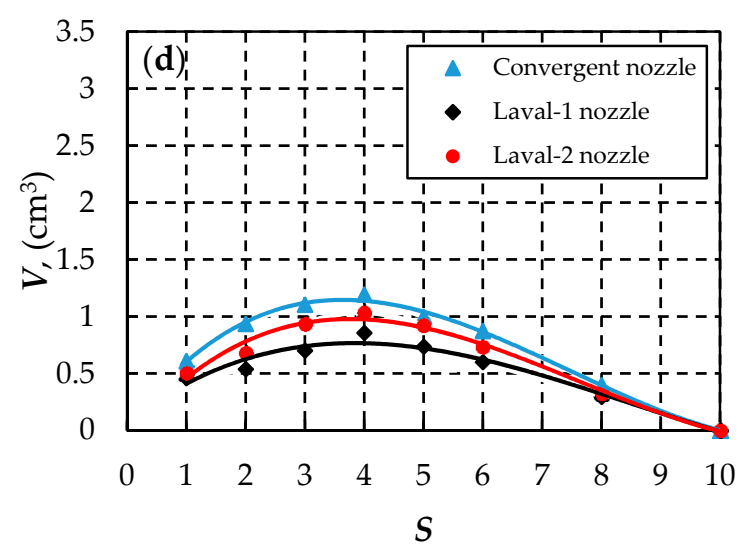

(d) $P_{a}=26 \mathrm{MPa}, P_{i}=40 \mathrm{MPa}$

Figure 7. Effect of nozzle configuration on rock erosion volume of the $\mathrm{SC}-\mathrm{CO}_{2}$ jet under different ambient pressures and constant inlet pressure: (a) $2 \mathrm{MPa}$; (b) $10 \mathrm{MPa}$; (c) $18 \mathrm{MPa}$; (d) $26 \mathrm{MPa}$.

As is depicted in Figure 7, on the whole the increasing ambient pressure reduces the maximum erosion volume of all the jets. This indicates a weakened intensity of rock erosion ability of the jets, which is attributed to the dramatic reduction of the pressure drop across the nozzles with the increasing ambient pressure, for less pressure energy could be transferred to the kinetic energy of the jets. Moreover, under the constant inlet pressure, the nozzle configuration has varying effects on the rock erosion ability of the $\mathrm{SC}-\mathrm{CO}_{2}$ jet at different ambient pressures. More specifically, compared with the convergent nozzle, the maximum increments of rock erosion volume caused by the Laval- 1 nozzle are about $23.8 \%, 21.8 \%$, and $13.1 \%$, corresponding to ambient pressures of 2,10 , and $18 \mathrm{MPa}$, respectively; while those caused by the Laval-2 nozzle are about $53.4 \%, 49.2 \%$, and $37.7 \%$, respectively. For the ambient pressure of $26 \mathrm{MPa}$, curves of the Laval nozzles are always below that of the convergent nozzle, which indicates the weaker erosion action of these two nozzles compared with that of the convergent nozzle. In addition, it is obvious from Figure 9 that the jets of all the three nozzles have shorter optimal standoff distances at ambient pressure of $2 \mathrm{MPa}$ than that at relatively high ambient pressure.

\subsection{Effect of Nozzle Configuration Under Different Ambient Pressures and Constant Pressure Drop}

Figure 8 shows the influence of nozzle configuration on the rock erosion performance of the SC- $\mathrm{CO}_{2}$ jet under four ambient pressures and constant nozzle pressure drop, $\Delta P$. In this group of experiments, $\Delta P$ was set constant as $30 \mathrm{MPa}$, and the fluid temperature was set constant as $330 \mathrm{~K}$. The standoff distances increased from 1 to 10 . The ambient pressure was sequentially set at 2, 10, 18, and $26 \mathrm{MPa}$. 


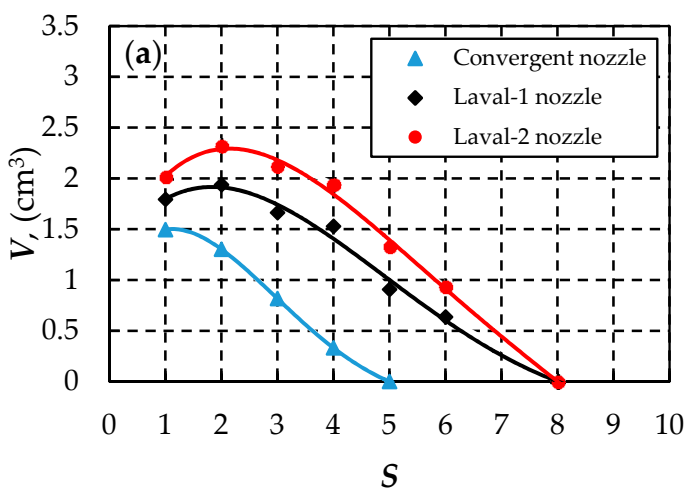

(a) $P_{a}=2 \mathrm{MPa}, \Delta P=30 \mathrm{MPa}$

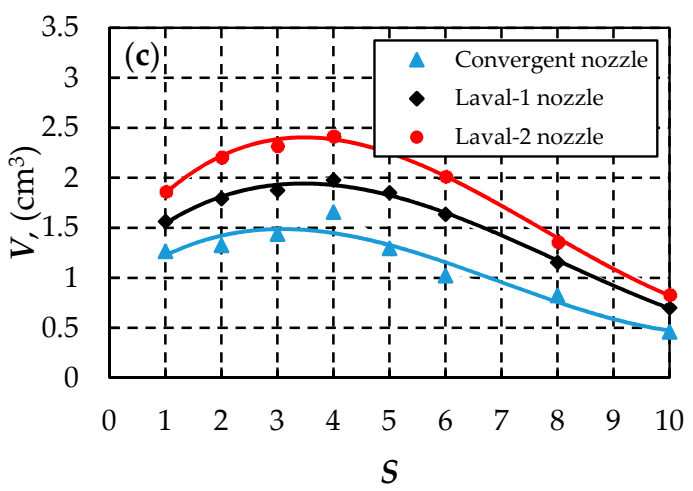

(c) $P_{a}=18 \mathrm{MPa}, \Delta P=30 \mathrm{MPa}$

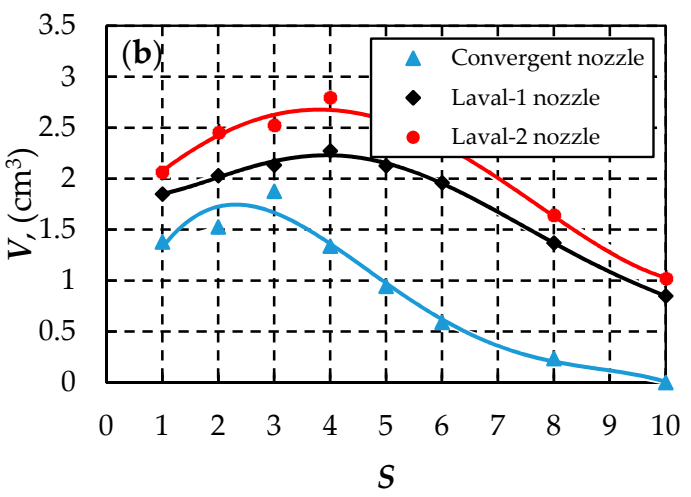

(b) $P_{a}=10 \mathrm{MPa}, \Delta P=30 \mathrm{MPa}$

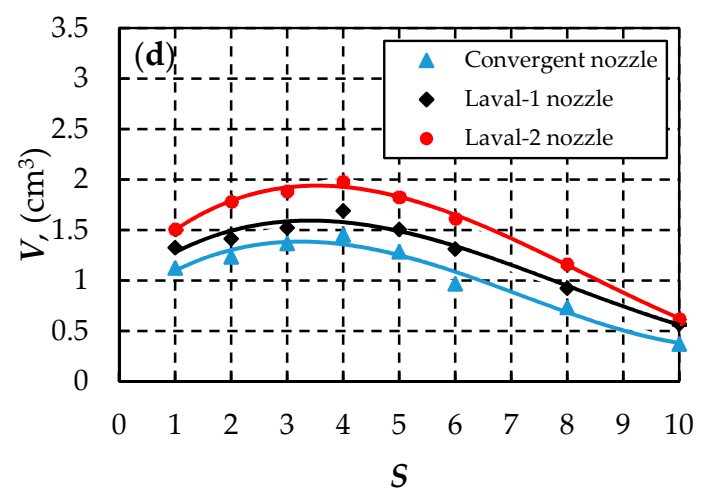

(d) $P_{a}=26 \mathrm{MPa}, \Delta P=30 \mathrm{MPa}$

Figure 8. Effect of nozzle configuration on rock erosion volume of the $\mathrm{SC}-\mathrm{CO}_{2}$ jet under different ambient pressures and constant $\triangle P:$ (a) $2 \mathrm{MPa}$; (b) $10 \mathrm{MPa}$; (c) $18 \mathrm{MPa}$; (d) $26 \mathrm{MPa}$.

As is illustrated in Figure 8, the ambient pressure has a significant effect on the erosion ability of all the jets discharging from different nozzles though the $\Delta P$ remains constant. The maximum erosion volume for the three nozzles increases when the ambient pressure is increased from 2 to $10 \mathrm{MPa}$. Then the further increase of ambient pressure reduces the maximum erosion volume. This suggests that, when the ambient pressure is below the critical pressure $7.38 \mathrm{MPa}$, the increasing ambient pressure can enhance the rock erosion ability of the $\mathrm{SC}-\mathrm{CO}_{2}$ jet, which is attributed to the increasing density and diffusivity of $\mathrm{SC}-\mathrm{CO}_{2}$ fluid with the increasing ambient pressure. The increase of ambient pressure above the critical pressure can weaken the erosion capability because of the growing fluid resistance [11]. Moreover, when compared to the convergent nozzle, the maximum erosion volumes of the Laval-1 nozzle show an increment of $29.5 \%, 21.8 \%, 19.3 \%$, and $16.4 \%$, corresponding to ambient pressures of 2, 10, 18, and $26 \mathrm{MPa}$, respectively; while those of the Laval-2 nozzle show an increment of $54.6 \%, 49.2 \%, 45.6 \%$, and $36.7 \%$, respectively. These data suggest that, when $\Delta P$ is constant, the enhancement of rock erosion ability of the $\mathrm{SC}-\mathrm{CO}_{2}$ jet caused by the Laval nozzles decreases with the increase of ambient pressure. Besides, it can be observed in the figure that the optimal standoff distances for the three nozzles at ambient pressure of $2 \mathrm{MPa}$ are significantly shorter than that at ambient pressures of 10,18, and $26 \mathrm{MPa}$.

\subsection{Effect of Nozzle Configuration Under Different Fluid Temperatures}

Figure 9 shows the effects of nozzle configuration on the erosion action of the jets under various fluid temperatures. In this group of experiments, the inlet and ambient pressures were set constant at 40 and $10 \mathrm{MPa}$, respectively. The standoff distance increased from 1 to 10 . The fluid temperature was sequentially adjusted from 290 to $350 \mathrm{~K}$. 


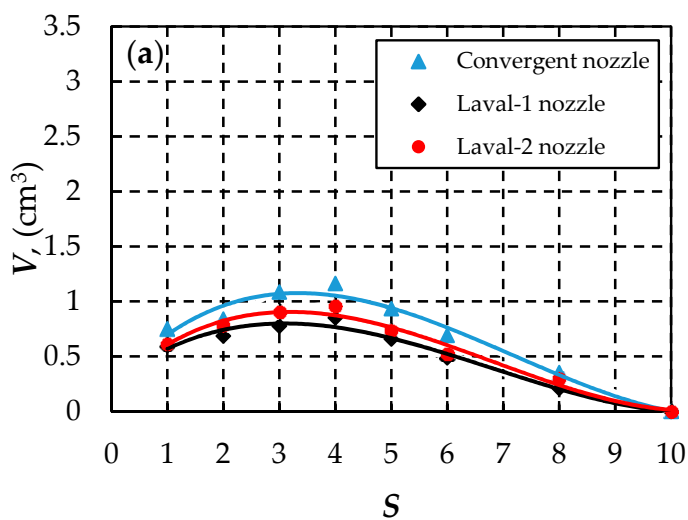

(a) $T=290 \mathrm{~K}$

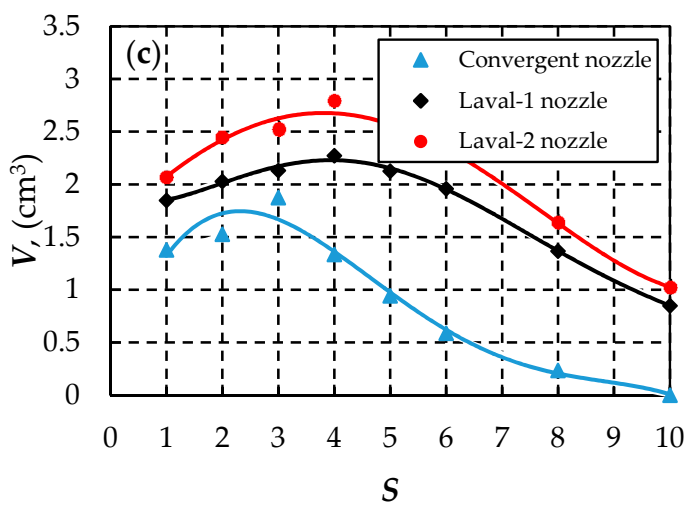

(c) $\mathrm{T}=330 \mathrm{~K}$

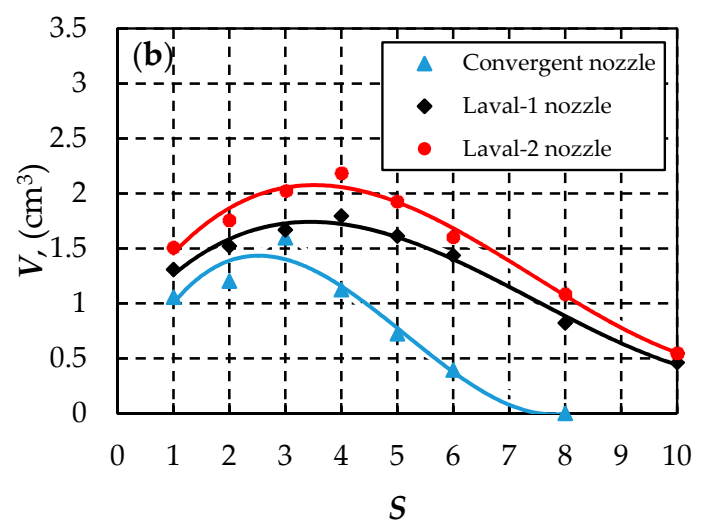

(b) $T=310 \mathrm{~K}$

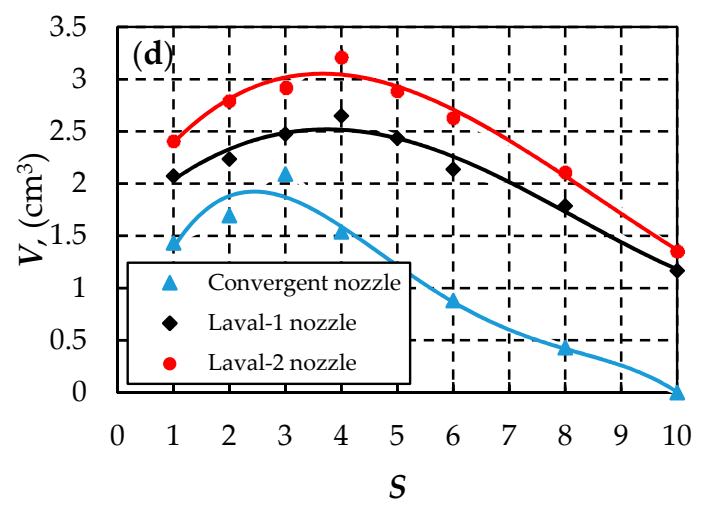

(d) $T=350 \mathrm{~K}$

Figure 9. Effect of nozzle configuration on rock erosion volume of the $\mathrm{SC}-\mathrm{CO}_{2}$ jet under different fluid temperatures.

As can be seen from the curves in Figure 9, the fluid temperature not only affects the erosion capability of the SC- $\mathrm{CO}_{2}$ jet, but also affects the enhancement of erosion performance achieved by using the Laval nozzles. Specifically, the maximum erosion volumes for the three nozzles show an increasing trend with the increasing fluid temperature. This indicates that the $\mathrm{SC}-\mathrm{CO}_{2}$ jet has a stronger erosion capability at relatively higher temperatures. This is due to the fact that with the growth of fluid temperature the diffusivity of the $\mathrm{SC}-\mathrm{CO}_{2}$ fluid increases. What is more, the increase of diffusivity is very significant when the temperature increases from a liquid temperature to a supercritical temperature, which results in the obvious enhancement of erosion ability of the SC- $\mathrm{CO}_{2}$ jet when the temperature increases from 290 to 310 K $[9,11]$. Moreover, compared with the commonly used convergent nozzle, the use of Laval- 1 nozzle increases the rock erosion volume by $12.5 \%, 21.8 \%$, and $26.7 \%$, respectively, corresponding to fluid temperature of 310,330 , and $350 \mathrm{~K}$, respectively; while the employ of Laval-2 nozzle increases the erosion volume by $37.2 \%, 49.2 \%$, and $53.7 \%$, respectively. These data indicate that, with the increase of fluid temperature, the enhancement of rock erosion ability of the $\mathrm{SC}-\mathrm{CO}_{2}$ jet by the Laval nozzles is more and more obvious though the inlet and ambient pressures remain constant. However, at temperature of $290 \mathrm{~K}$, the convergent nozzle has better erosion performance than both the two Laval nozzles, which means that the Laval nozzle cannot effectively play its role in accelerating the liquid $\mathrm{CO}_{2}$ fluid at temperature of $290 \mathrm{~K}$.

\section{Discussion}

From the experimental results, the nozzle configuration has significant effects on the rock erosion characteristics of the SC- $\mathrm{CO}_{2}$ jet. How nozzle configuration influences rock erosion ability is likely to 
depend on the nozzle configuration and the ratio of the inlet pressure and the ambient pressure. This is due to the fact that the pressure ratio can have large effects on the acceleration process of the $\mathrm{SC}-\mathrm{CO}_{2}$ fluid inside the different nozzles which in turn directly affects the flow characteristics as well as the impingement characteristics of the high-speed $\mathrm{SC}-\mathrm{CO}_{2}$ jet. To further understand the mechanism of effects of nozzle configuration on the rock erosion characteristics of the $\mathrm{SC}-\mathrm{CO}_{2}$ jet, a preliminary analysis was performed as follows.

According to the theory of erosion of materials by jet impact, when the fluid and the rock specimens remain unchanged, the erosion intensity of the jet on the rock specimens is largely dependent on the impact velocity which determines the magnitude of the impact loading and the stress wave energy $[44,45]$. Moreover, the impact velocity is affected by the pressure ratio which drives the fluid to flow in the nozzle, and the nozzle configuration which determines the acceleration of the fluid inside the nozzle $[26,27,29]$. As described in Section 2.2, when using nozzles with different configurations, the jet will have different impact velocities and structures under the same pressure condition. The impact velocity and structure of the jet can be judged and analyzed by the critical pressure ratios.

According to Equation (2), the calculated critical pressure ratio, $R_{1}$, is 0.55 for the convergent nozzle. Simultaneously, in light of Equations (3)-(5), the calculated critical pressure ratios, $R_{2}, R_{a 1}$, and $R_{a 2}$ are $0.13,0.57$, and 0.92 , respectively. For the experiments on the effect of nozzle configuration on the erosion ability of the SC- $\mathrm{CO}_{2}$ jet under various inlet pressures, the pressure ratios were plotted in Figure 10. As shown in the figure, at inlet pressure of $20 \mathrm{MPa}$, the pressure ratio is very close to $R_{1}$ and $R_{a 1}$. For the convergent nozzle, the flow of the jet approaches the critical state and almost no shock wave is formed at this pressure ratio; while for the Laval nozzles, this will cause strong normal shock waves formed in the jet near the nozzle exit due to compression of jet fluid by ambient fluid, resulting in the largely reduced impact velocity and the weak impingement on the specimens $[26,27,29]$. As a result, the convergent nozzle has a greater erosion capability than the Laval nozzles, as shown in Figure 6a. Besides, with the increase of inlet pressure, for the convergent nozzle, the pressure ratio is getting lower than the critical value, $R_{1}$, resulting in more and more intense expansion of the jet ejected from the nozzle exit $[26,29]$. This will make the jet cannot focus enough energy to effectively impact and erode the specimen, which is likely to be the reason for the reduction of the optimal standoff distance, as shown in Figure $6 \mathrm{~b}-\mathrm{d}$. For the Laval nozzles, the pressure ratio is getting closer to the critical value, $R_{2}$, with increasing inlet pressure. This will reduce the intensity of the shock waves in the jet flow and enhance the acceleration of $\mathrm{SC}-\mathrm{CO}_{2}$ fluid, and thus enhance erosion capability of the jet $[27,29]$ so that the maximum enhanced erosion volume increases when raising the inlet pressure, as described in Section 4.2.

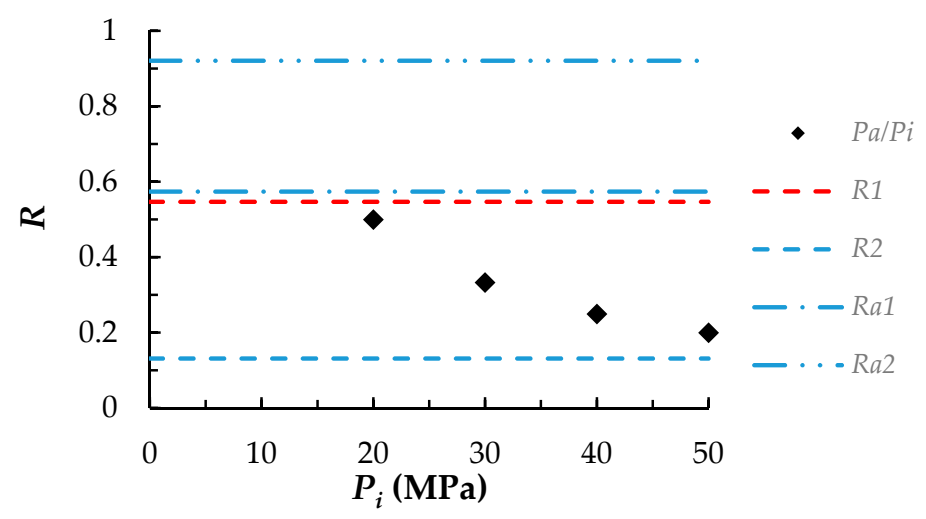

Figure 10. Distribution of pressure ratio under different inlet pressures at constant ambient pressure of $10 \mathrm{MPa}$.

Moreover, for the experiments under various ambient pressure and constant inlet pressure, the pressure ratio grows up with increasing ambient pressure, as shown in Figure 11. 


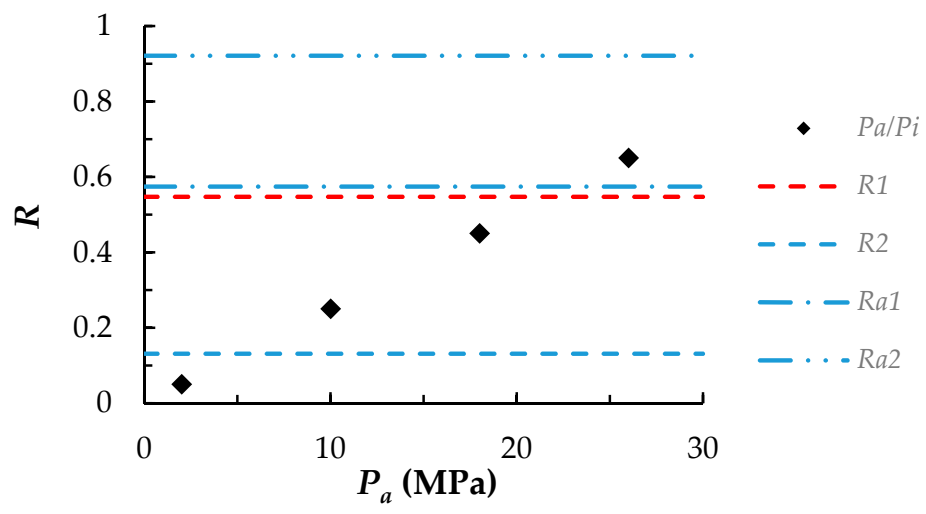

Figure 11. Distribution of pressure ratio under different ambient pressure at constant inlet pressure of $40 \mathrm{MPa}$.

For the Laval nozzle, the increasing pressure ratio above $R_{2}$ will cause the stronger and stronger normal shock waves near the nozzle exit $[26,29]$. Then the normal shock waves attenuate the acceleration of the SC- $\mathrm{CO}_{2}$ fluid, thus, resulting in the gradually decreasing enhancement of rock erosion ability of the $\mathrm{SC}-\mathrm{CO}_{2}$ jet by the Laval nozzle, as described in Section 4.3. At an ambient pressure of $26 \mathrm{MPa}$ the pressure ratio is greater than $R a_{1}$; the normal shock waves will locate inside the Laval nozzle and obviously reduce the impact velocity of the jet [26,29], which results in the weaker erosion ability of the Laval nozzles than that of the convergent nozzle, as shown in Figure $7 \mathrm{~d}$. Furthermore, at ambient pressure of $2 \mathrm{MPa}$, the pressure ratio is less than $R_{2}$ and far below $R_{1}$. This leads to intense expansion of the jets ejected from the nozzles $[27,29]$ and the smaller optimal standoff distances than that at ambient pressures of 10,18 , and $26 \mathrm{MPa}$.

Besides, for the experiments under various ambient pressure and constant $\Delta P$, the pressure ratio increases with the growth of ambient pressure under constant $\Delta P$, as illustrated in Figure 12.

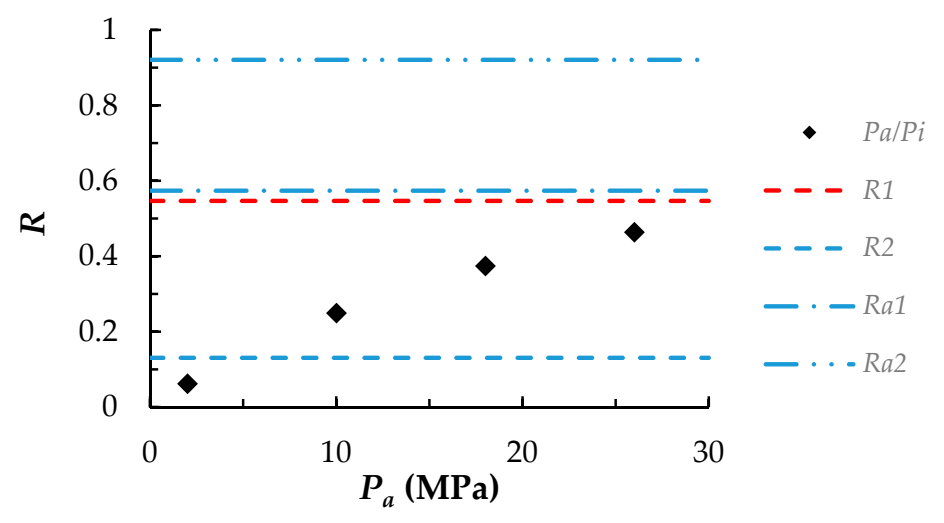

Figure 12. Pressure ratio as a function of ambient pressure under constant pressure difference of $30 \mathrm{MPa}$.

Similarly, the higher the pressure ratio is, the stronger the normal shock wave near the nozzle exit will be [26,29]. As a result, the enhancement decreases with increasing ambient pressure under constant $\Delta P$, as described in Section 4.4. Likewise, the intense expansion of the $\mathrm{SC}^{-} \mathrm{CO}_{2}$ jet at very low pressure ratio $[27,29]$ results in the smaller optimal standoff distances at ambient pressure of $2 \mathrm{MPa}$, as shown in Figure 8a.

In addition, for the experiments under various fluid temperatures, the pressure ratio remains constant, however, the enhancement of erosion ability of the $\mathrm{SC}-\mathrm{CO}_{2}$ jet by the Laval nozzles still shows an increasing trend when the fluid temperature rises from 310 to $350 \mathrm{~K}$, as described in Section 4.5. This is mostly due to the fact that the acceleration of fluid in the divergent section of the Laval nozzle is taking advantage of the compressibility of the fluid $[26,28]$. The compressibility of the SC-CO 
fluid increases as the temperature rises. As a result, the enhancement keeps an upward tendency with increasing fluid temperature. Furthermore, at fluid temperature of $290 \mathrm{~K}$ below the critical temperature $(304.13 \mathrm{~K})$, the Laval nozzles have weaker erosion capability than that of the convergent nozzle, as shown in Figure 9a, which seems attributed to the low compressibility of the liquid $\mathrm{CO}_{2}$.

Another interesting phenomenon that can be observed in Figures 6-9 is that, the $\mathrm{SC}_{-} \mathrm{CO}_{2}$ jet issuing from the Laval-1 nozzle always has a weaker erosion ability than that discharging from the Laval-2 nozzle. This is likely due to the fact that the inner profile of the Laval-2 nozzle is much smoother than that of the Laval-1 nozzle, as shown in Figure 3. For Laval-1 nozzle, the unsmooth inner profile makes the flow inside the nozzle more turbulent and shock waves form at the corner [29], which results in more energy loss of the flow. As a result, the erosion ability is reduced.

\section{Conclusions}

To improve erosion ability of the $\mathrm{SC}-\mathrm{CO}_{2}$ jet for better practical applications, effects of nozzle configuration on rock erosion were experimentally investigated with respect to the macroscopic appearances and erosion volumes of eroded specimens. The main results are described as follows:

1. The macroscopic appearances of specimens eroded by $\mathrm{SC}-\mathrm{CO}_{2}$ jets discharging from different nozzles display similar typical "drilling type" damage. Small pieces of rock breakage can be observed around the erosion pits caused by the Laval nozzles, while the pits eroded by the convergent nozzle are relatively flat and smooth.

2. Compared with the convergent nozzle, the Laval nozzles can enhance the erosion ability of the $\mathrm{SC}-\mathrm{CO}_{2}$ jet more and more significantly with increasing inlet pressure; whilst at relatively lower inlet pressure of $20 \mathrm{MPa}$, they reduce the erosion capacity.

3. Under constant inlet pressure, the maximum increments of erosion capability caused by the Laval nozzles are reduced by the increasing ambient pressure. Besides, at ambient pressure of $26 \mathrm{MPa}$, the Laval nozzles turn to weaken the erosion ability. When $\Delta P$ is constant, the enhancements caused by the Laval nozzles decrease with growing ambient pressure.

4. As the fluid temperature rises, the enhancements of erosion capacity produced by the Laval nozzles increase. Moreover, the Laval nozzles weaken the erosion intensity at a temperature of $290 \mathrm{~K}$, which puts $\mathrm{CO}_{2}$ in liquid state.

5. The $\mathrm{SC}-\mathrm{CO}_{2}$ jet issuing from the Laval-2 nozzle with a smooth inner profile always has a greater erosion ability than that discharging from the Laval-1 nozzle.

Acknowledgments: This research is financially supported by the National Key Basic Research Program of China (No. 2014CB239203), the National Natural Science Foundation of China (No. 51474158) and the Hubei Provincial Natural Science Foundation of China (No. 2016CFA088).

Author Contributions: Man Huang, Yong Kang, and Yi Hu conceived and designed the facilities and the experiments; Man Huang, Yi Hu, Can Cai, and Feng Chen performed the experiments; Man Huang, Xiaochuan Wang and Deng Li analyzed the data and made the analysis; Man Huang wrote the paper.

Conflicts of Interest: The authors declare no conflict of interest.

\section{Nomenclatures}

$P_{C}$

$T_{C}$

A

$M a$

$v$

$P_{i}$

$P_{a}$

$R_{1}, R_{2}, R_{a 1}, R_{a 2}$

k critical pressure of $\mathrm{CO}_{2}, \mathrm{MPa}$

critical temperature of $\mathrm{CO}_{2}, \mathrm{~K}$

cross-sectional area of the nozzle flow path, $\mathrm{m}^{3}$

Mach number

flow velocity, $\mathrm{m} / \mathrm{s}$

inlet pressure, $\mathrm{MPa}$

ambient pressure, $\mathrm{MPa}$

critical pressure ratios

adiabatic exponent 


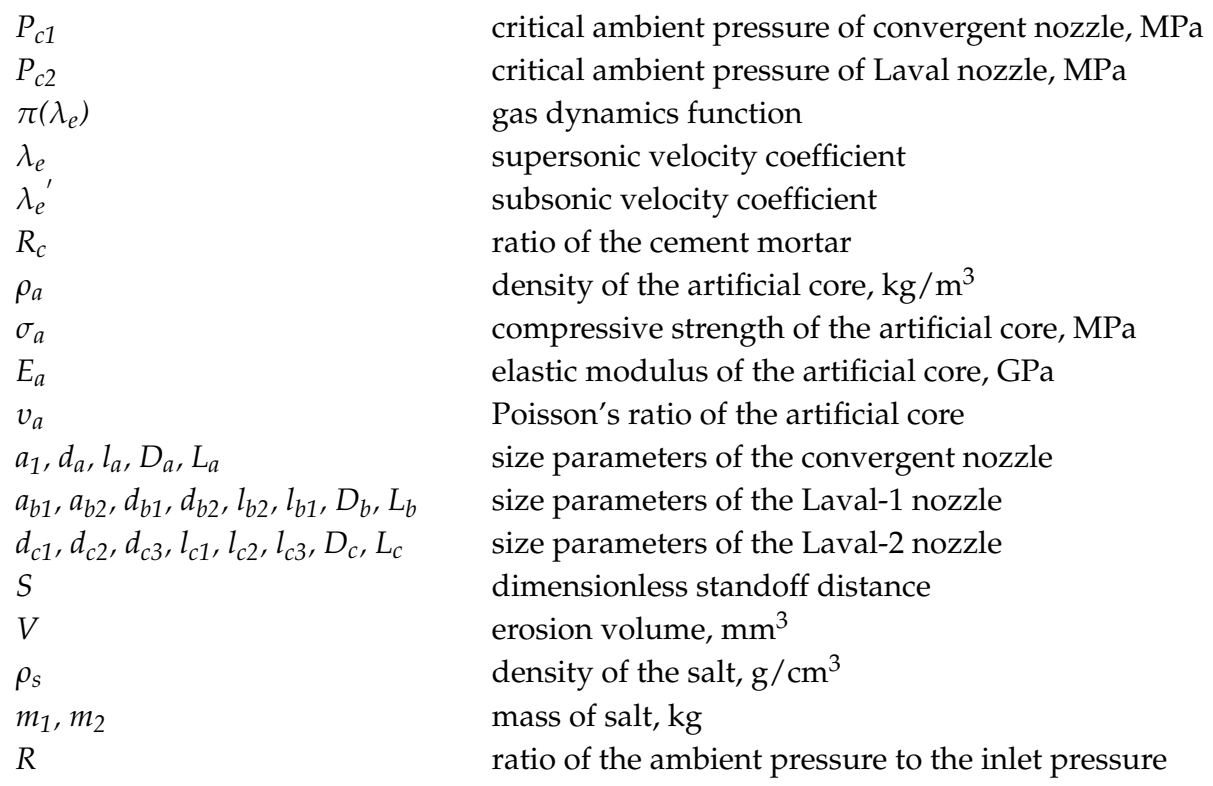

\section{References}

1. Knez, Ž.; Markočič, E.; Leitgeb, M.; Primožič, M.; Hrnčič, M.K.; Škerget, M. Industrial applications of supercritical fluids: A review. Energy 2014, 77, 235-243. [CrossRef]

2. Bellan, J. Supercritical (and subcritical) fluid behavior and modeling: Drops, streams, shear and mixing layers, jets and sprays. Prog. Energ. Combust. 2000, 26, 329-366. [CrossRef]

3. Shen, Z.; Wang, H.; Li, G. Feasibility analysis of coiled tubing drilling with supercritical carbon dioxide. Petrol. Explor. Dev. 2010, 37, 743-747. [CrossRef]

4. Gupta, A.P.; Gupta, A.; Langlinais, J. Feasibility of supercritical carbon dioxide as a drilling fluid for deep underbalanced drilling operation. In Proceedings of SPE Annual Technical Conference and Exhibition, Dallas, TX, USA, 9-12 October 2005. [CrossRef]

5. ALAdwani, F.A. Mechanistic Modeling of an Underbalanced Drilling Operation Utilizing Supercritical Carbon Dioxide. Ph. D. Thesis, Louisiana State University, LA, USA, August 2007.

6. Middleton, R.S.; Carey, J.W.; Currier, R.P.; Hyman, J.D.; Kang, Q.; Karra, S.; Jiménez-Martínez, J.; Porter, M.L.; Viswanathan, H.S. Shale gas and non-aqueous fracturing fluids: Opportunities and challenges for supercritical $\mathrm{CO}_{2}$. Appl. Energy 2015, 147, 500-509. [CrossRef]

7. Wang, H.; Li, G.; Shen, Z. A feasibility analysis on shale gas exploitation with supercritical carbon dioxide. Energ. Source A 2012, 34, 1426-1435. [CrossRef]

8. Fang, C.; Chen, W.; Amro, M. Simulation study of hydraulic fracturing using super critical $\mathrm{CO}_{2}$ in shale. In Proceedings of Abu Dhabi International Petroleum Exhibition and Conference, Abu Dhabi, UAE, 10-13 November 2014. [CrossRef]

9. Du, Y.K.; Wang, R.H.; Ni, H.J.; Li, M.K.; Song, W.Q.; Song, H.F. Determination of rock-breaking performance of high-pressure supercritical carbon dioxide jet. J. Hydrodyn. 2012, 24, 554-560. [CrossRef]

10. Lv, Q.; Long, X.P.; Kang, Y.; Xiao, L.Z.; Wu, W. Numerical investigation on the expansion of supercritical carbon dioxide jet. IOP Conf. Ser. Matesr. Sci. Eng. 2013, 52, 072011. [CrossRef]

11. Tian, S.C.; He, Z.G.; Li, G.S.; Wang, H.Z.; Shen, Z.H.; Liu, Q.L. Influences of ambient pressure and nozzle-to-target distance on $\mathrm{SC}-\mathrm{CO}_{2}$ jet impingement and perforation. J. Nat. Gas Sci. Eng. 2016, 29, 232-242. [CrossRef]

12. Wang, H.Z.; Li, G.S.; Shen, Z.H.; Tian, S.C.; Sun, B.J.; He, Z.G.; Lu, P.Q. Experiment on rock breaking with supercritical carbon dioxide jet. J. Petrol. Sci. Eng. 2015, 127, 305-310. [CrossRef]

13. Hu, Y.; Kang, Y.; Wang, X.; Li, X.; Huang, M.; Zhang, M. Experimental and theoretical analysis of a supercritical carbon dioxide jet on wellbore temperature and pressure. J. Nat. Gas Sci. Eng. 2016, 36 Pt A, 108-116. [CrossRef]

14. Zhou, Z.; Lu, Y.; Tang, J.; Zhang, X.; Li, Q. Numerical simulation of supercritical carbon dioxide jet at well bottom. Appl. Therm. Eng. 2017, 121, 210-217. [CrossRef] 
15. Huang, M.; Kang, Y.; Long, X.; Wang, X.; Hu, Y.; Li, D.; Zhang, M. Effects of a nano-silica additive on the rock erosion characteristics of a SC- $\mathrm{CO}_{2}$ jet under various operating conditions. Appl. Sci. 2017, 7, 153. [CrossRef]

16. He, Z.G.; Li, G.S.; Wang, H.Z.; Shen, Z.H.; Tian, S.C.; Lu, P.Q.; Guo, B. Numerical simulation of the abrasive supercritical carbon dioxide jet: The flow field and the influencing factors. J. Hydrodyn. 2016, 28, 238-246. [CrossRef]

17. Wang, H.Z.; Li, G.S.; Tian, S.C.; Cheng, Y.X.; He, Z.G.; Yu, S.J. Flow field simulation of supercritical carbon dioxide jet: Comparison and sensitivity analysis. J. Hydrodyn. 2015, 27, 210-215. [CrossRef]

18. Wang, R.H.; Huo, H.J.; Huang, Z.Y.; Song, H.F.; Ni, H.J. Experimental and numerical simulations of bottom hole temperature and pressure distributions of supercritical $\mathrm{CO}_{2}$ jet for well-drilling. J. Hydrodyn. 2014, 26, 226-233. [CrossRef]

19. Kolle, J.J. Coiled-tubing drilling with supercritical carbon dioxide. In Preceeding of the SPE/CIM International Conference on Horizontal Well Technology, Calgary, AB, Canada, 6-8 November 2000. [CrossRef]

20. Huang, F.; Lu, Y.; Tang, J.; Ao, X.; Jia, Y. Reasearch on erosion of shale impacted by supercritical carbon dioxide jet. Chin. J. Rock Mech. Eng. 2015, 34, 787-794. [CrossRef]

21. He, Z.; Li, G.; Tian, S.; Wang, H.; Shen, Z.; Li, J. SEM analysis on rock failure mechanism by supercritical $\mathrm{CO}_{2}$ jet impingement. J. Petrol. Sci. Eng. 2016, 146, 111-120. [CrossRef]

22. Du, Y.; Wang, R.; Ni, H. Rock-breaking experimental study on the supercritical carbon dioxide swirl jet. J. Basic Sci. Eng. 2013, 21, 1078-1083. [CrossRef]

23. Tian, S.; Zhang, Q.; Li, G.; He, Z.; Liu, H.; Liu, X. Experimental study on rock-erosion features with conbieng swirling and round jet of supercritical caibon dioxde. Explos. Shock 2016, 36, 189-197. [CrossRef]

24. Cheng, Y.; Li, G.; Shen, Z.; Wang, H.; Li, J. Impact pressure and parametric sensivity analysis of supercritical $\mathrm{CO}_{2}$ jet. Acta Pet. Sin. 2014, 35, 765-770. [CrossRef]

25. Long, X.; Liu, Q.; Ruan, X.; Kang, Y.; Lyu, Q. Numerical investigation of the flow of supercritical carbon dioxide injected into the bottom hole during drilling with special emphasis on the real gas effects. J. Nat. Gas Sci. Eng. 2016, 34, 1044-1053. [CrossRef]

26. Zhao, C.; Jiang, Y. Gas Jet Dynamics; Beijing Institute of Technology Press: Beijing, China, 1998; pp. 37-60, 107-144.

27. Chapman, A.J.; Walker, W.F. Introductory Gas Dynamics; Holt, Rinehart and Winston: New York, NY, USA, 1971.

28. Shapiro, A.H. The Dynamics and Thermodynamics of Compressible Fluid Flow; John Wiley \& Sons: New York, NY, USA, 1953.

29. Courant, R.; Friedrichs, K.O. Supersonic Flow and Shock Waves; Springer Science \& Business Media: Dordrecht, The Netherlands, 1999; Volume 21.

30. Zaman, K. Asymptotic spreading rate of initially compressible jets - experiment and analysis. Phys. Fluids 1998, 10, 2652-2660. [CrossRef]

31. Wang, X.; Heberlein, J.; Pfender, E.; Gerberich, W. Effect of nozzle configuration, gas pressure, and gas type on coating properties in wire arc spray. J. Therm. Spray Technol. 1999, 8, 565-575. [CrossRef]

32. Kainz, S.; Brinkmann, A.; Leitner, W.; Pfaltz, A. Iridium-catalyzed enantioselective hydrogenation of imines in supercritical carbon dioxide. J. Am. Chem. Soc. 1999, 121, 6421-6429. [CrossRef]

33. Koch, D.; Leitner, W. Rhodium-catalyzed hydroformylation in supercritical carbon dioxide. J. Am. Chem. Soc. 1998, 120, 13398-13404. [CrossRef]

34. Wood, C.D.; Cooper, A.I. Synthesis of macroporous polymer beads by suspension polymerization using supercritical carbon dioxide as a pressure-adjustable porogen. Macromolecules 2001, 34, 5-8. [CrossRef]

35. Eslamian, M.; Pophali, A.; Bussmann, M.; Tran, H. Breakup of brittle deposits by supersonic air jet: The effects of varying jet and deposit characteristics. Int. J. Impact Eng. 2009, 36, 199-209. [CrossRef]

36. Man, H.C.; Duan, J.; Yue, T.M. Dynamic characteristics of gas jets from subsonic and supersonic nozzles for high pressure gas laser cutting. Opt. Laser Technol. 1998, 30, 497-509. [CrossRef]

37. Yi, S.H.; Zhao, Y.X.; He, L.; Zhang, M.L. Supersonic and Hypersonic Nozzle Design; National Defense Industry Press: Beijing, China, 2013; pp. 11-24.

38. Hocheng, H.; Weng, C. Hydraulic erosion of concrete by a submerged jet. J. Mater. Eng. Perform. 2002, 11, 256-261. [CrossRef] 
39. Hu, D.; Li, X.; Tang, C.; Kang, Y. Analytical and experimental investigations of the pulsed air-water jet. J. Fluid. Struct. 2015, 54, 88-102. [CrossRef]

40. Wei, S. Gas Dynamics (Part 2); National Defense Industry Press: Beijing, China, 1984; pp. 55-122.

41. Wu, R.L.; Wang, Z.Y. Design of Wind Tunnel; Beihang University Press: Beijing, China, 1985; pp. $138-171$.

42. Gnirk, P.F.; Grams, W.H. Rock drilling with pulsed high-velocity water jets. In Proceedings of the 14th US Symposium on Rock Mechanics (USRMS), University Park, PA, USA, 11-14 June 1972.

43. Daniel, I.M. Experimental studies of water jet impact on rock and rocklike materials. In Proceedings of the 3rd International Symposium on Jet Cutting Technology, Chicago, IL, USA, 11-13 May 1976; pp. 27-46.

44. Lu, Y.; Huang, F.; Liu, X.; Ao, X. On the failure pattern of sandstone impacted by high-velocity water jet. Int. J. Impact Eng. 2015, 76, 67-74. [CrossRef]

45. Momber, A.W. Deformation and fracture of rocks due to high-speed liquid impingement. Int. J. Fract. 2004, 130, 683-704. [CrossRef]

(C) 2017 by the authors. Licensee MDPI, Basel, Switzerland. This article is an open access article distributed under the terms and conditions of the Creative Commons Attribution (CC BY) license (http://creativecommons.org/licenses/by/4.0/). 